\title{
A Safe and Effective Mucosal RSV Vaccine Consisting of RSV Phosphoprotein and Flagellin Variant
}

Bali Zhao ${ }^{1,2}$, Jingyi Yang ${ }^{1,2}$, Bing $\mathrm{He}^{3}$, Xian $\mathrm{Li}^{2}$, Hu Yan ${ }^{2}$, Shuning Liu ${ }^{3}$, Yi Yang ${ }^{2}$,

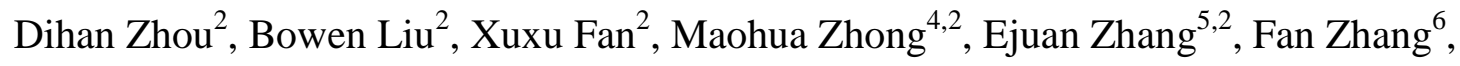
Yue Zhang ${ }^{2}$, Yao-Qing Chen ${ }^{3}$, Shibo Jiang ${ }^{7,1 \dagger}$ and Huimin Yan ${ }^{1,2 \dagger, \star}$

${ }^{1}$ Vaccine and Immunology Research Center, Translational Medical Research Institute, Shanghai Public Health Clinical Center, Fudan University, Shanghai, 201508, China ${ }^{2}$ Mucosal Immunity Research Group, State Key Laboratory of Virology, Wuhan Institute of Virology, Chinese Academy of Sciences, Wuhan 430071, China.

${ }^{3}$ School of Public Health (Shenzhen), Sun Yat-sen University, Shenzhen 518107, China

${ }^{4}$ Institute of Infection, Immunology and Tumor Microenvironment, Hubei Province Key Laboratory of Occupational Hazard Identification and Control, Medical College, Wuhan University of Science and Technology, Wuhan 430065, China.

${ }^{5}$ Medical Science Research Center, Zhongnan Hospital of Wuhan University, Wuhan 430071, China.

${ }^{6}$ The Core Facility and Technical Support, Wuhan Institute of Virology, Chinese Academy of Sciences, Wuhan 430071, China.

${ }^{7}$ Key Laboratory of Medical Molecular Virology (MOE/NHC/CAMS), School of Basic Medical Sciences, Shanghai Medical College, Fudan University, Shanghai 200032, China.

*These authors contributed equally to this work.

${ }^{\star}$ Lead contact: yanhuimin@shphc.org.cn (H.Y.)

†Correspondence: shibojiang@fudan.edu.cn (S.J.), yanhuimin@shphc.org.cn (H.Y.) 


\section{SUMMARY}

2 Respiratory syncytial virus (RSV) is a major cause of serious acute lower respiratory

3 tract infection in infants and the elderly. No licensed RSV vaccine available thus far

4 calls for the development of vaccines with new target(s) and vaccination strategies.

5 Here, we constructed a recombinant protein, designated P-KFD1, comprised of RSV

6 phosphoprotein (P) and E. coli K12 strain-derived flagellin variant KFD1. Intranasal

7 (i.n.) immunization with P-KFD1 inhibits RSV replication in both upper and lower

8 respiratory tract, and protects mice against lung disease without vaccine-enhanced

9 disease (VED). The P-specific $\mathrm{CD}^{+}{ }^{+} \mathrm{T}$ cells provoked by P-KFD1 i.n. immunization,

10 either reside in or migrate to respiratory tract, mediate protection against RSV

11 infection. Sc-RNA seq and carboxyfluorescein succinimidyl ester (CFSE) labeled cell

12 transfer further characterized the Th1 and Th17 responses induced by P-KFD1.

13 Finally, we found the anti-viral protection depends on either IFN- $\gamma$ or IL-17A.

14 Collectively, P-KFD1 is promising as a safe and effective mucosal vaccine candidate

15 to prevent RSV infection.

KEYWORDS: RSV vaccine; P-KFD1; VED; CD4 ${ }^{+}$T cells; sc-RNA seq; Th17

HIGHLIGHTS:

- A new subunit RSV vaccine candidate with new target and vaccination strategy, $\mathrm{P}-\mathrm{KFD} 1$, is designed and generated

- Intranasal immunization with P-KFD1 protects mice against RSV infection and averts vaccine-enhanced disease 
- Sc-RNA seq and CFSE-labelled cell transfer identified characteristics of the protective $\mathrm{CD} 4^{+} \mathrm{T}$ cells

- Local and peripheral $\mathrm{CD}^{+} \mathrm{T}$ cells provide protection against RSV infection dependent on either IFN- $\gamma$ or IL-17A

\section{INTRODUCTION}

Human respiratory syncytial virus (RSV) was first isolated and identified as an important cause of bronchiolitis in infants as early as 1956 (Blount et al., 1956; Chanock and Finberg, 1957). It remains a major cause of severe acute lower respiratory tract infection (ALRI) not only in infants, but also in young children, the elderly, and immunocompromised populations worldwide (Chemaly et al., 2014; Falsey et al., 2005; Nair et al., 2010). RSV infection can result in severe complications, including bronchiolitis or pneumonia, often with acute respiratory distress, requiring hospitalization and creating a heavy medical cost and burden for treatment and prevention all over the world. In 2015 alone, RSV infection resulted in about 3.2 million episodes of hospitalization across the globe and 59,600 deaths in children younger than 5 years (Shi et al., 2017). A recent multi-site case-control study found that RSV had the greatest etiological fraction as high as $31.1 \%$ of all bacteria and virus pathogens that caused severe pneumonia requiring hospital admission in children from Africa and Asia (Group, 2019). Even worse, natural RSV infection does not elicit long-lasting immunity, and repeated infections occur throughout life (Glezen et al., 1986; Henderson et al., 1979). Only one licensed monoclonal antibody product (Palivizumab) is currently used to reduce the frequency of severe disease in the 
1 high-risk neonates (Group, 1998). The development of a safe and effective RSV

2 vaccine has been elusive thus far.

The intramuscularly administered formalin-inactivated RSV (FI-RSV) vaccine

4 primed for enhanced illness in infants on natural RSV infection, this phenomenon was

5 replicable in animal models and named as vaccine-enhanced disease (VED) (Chin et

6 al., 1969; Fulginiti et al., 1969; Kapikian et al., 1969; Kim et al., 1969; Waris et al.,

7 1996). Intensive investigation showed that VED is usually involved in Th2-biased

8 immune response and substantial binding antibodies (Ruckwardt et al., 2019).

9 Subsequent studies then adopted subunit-based vaccines, mostly by targeting cell

10 surface fusion (F) protein or attachment glycoprotein $(G)$, owing to their

11 immunogenicity for inducing neutralizing antibodies (Graham et al., 2015). However,

12 G protein-based vaccines also primed for immunopathology in animals (Johnson et

13 al., 1998; Openshaw et al., 1992; Tebbey et al., 1998), making G-targeted vaccines much more complicated. The elucidation of RSV F protein pre-fusion (pre-F) conformation (McLellan et al., 2013b) and its potential as an immunogen to induce potent neutralizing antibodies (Crank et al., 2019; Marcandalli et al., 2019; McLellan et al., 2013a) gave new hope for the development of F protein-based RSV vaccines. However, some previous clinical studies of post-fusion $\mathrm{F}$ (post-F)-based vaccines have failed (Ruckwardt et al., 2019). Consequently, new RSV vaccine targets and vaccination strategies warrant intensive investigation. 
1 upper and lower respiratory tracts if mucosal immunity could be elicited effectively in

2 the respiratory mucosa (Yang and Varga, 2014). Moreover, appropriate immunization

3 routes, such as intranasal (i.n.) administration, and specific adjuvant formulations to

4 induce potent and broad mucosal immune responses are needed. Therefore, we first

5 chose the cholera toxin B subunit (CTB) as a mucosal adjuvant to test whether the

$6 \quad$ RSV internal phosphoprotein $(\mathrm{P})$, nucleoprotein $(\mathrm{N})$, non-structural protein 1 (NS-1)

7 and M2-1 could be potential vaccine targets in BALB/c mice. We found that i.n.

8 administration of $\mathrm{P}$, together with $\mathrm{CTB}(\mathrm{P}+\mathrm{CTB})$, significantly reduced viral loads in

9 both noses and lungs of mice upon RSV challenge compared with mock immunized mice. This encouraging result urged us to further evaluate $\mathrm{P}$ as a vaccine target by 11 engaging more mucosal adjuvants and immunization strategies.

However, certain degree of increased inflammatory cell infiltration and mucus

production were observed in the $\mathrm{P}+\mathrm{CTB}$ immunized mice compared to saline immunized mice post RSV challenge, suggesting potential vaccine-induced immunopathogy. Thus, we further tried another mucosal adjuvant flagellin (Mizel and Bates, 2010), and integrated flagellin with the newly identified vaccine target $P$, as we did for the development of anti-caries vaccines (Bao et al., 2015; Sun et al., 2012; Yang et al., 2017). The resultant fusion protein-based vaccine P-KFD1 was comprised of phosphoprotein (P) of RSV and E. coli K12 strain-derived flagellin (KF) with deletion of its hypervariable domain (KFD1) (Donnelly and Steiner, 2002; Yang et al., 2013), where the P and KFD1 were covalently coupled. Here, we report that i.n. 
1 immunization with P-KFD1 protects mice against RSV infection, as well as lung

2 disease.

$3 \quad$ RESULTS

$4 \quad$ P-specific immune responses induced by intranasal immunization with P-KFD1

5 or $\mathbf{P}+\mathbf{C T B}$ protect mice against $\mathrm{RSV}$ infection

6 We generated a recombinant protein P-KFD1 (Figures S1A and S1B), and

7 investigated the immunogenicity and anti-viral efficacy of P-KFD1 as a potential

8 mucosal subunit RSV vaccine targeting on P. P-KFD1 retains Toll like receptor 5

9 (TLR5) activity at a marginal lower level than full length KF (Figure S1C). We

10 firstly evaluated the immunogenicity of $\mathrm{P}$ by i.n. immunization with P-KFD1 or

11 cholera toxin B subunit (CTB) adjuvanted P protein in BALB/c mice. Briefly, $20 \mu \mathrm{g}$

12 of P-KFD1 in saline or $10 \mu \mathrm{g}$ of $\mathrm{P}$ protein mixed with $2 \mu \mathrm{g}$ of $\mathrm{CTB}(\mathrm{P}+\mathrm{CTB})$ were

13 prepared as one dose of immunogen. BALB/c mice were immunized with P-KFD1,

14 P+CTB or saline only for sham control, respectively, at weeks (w) 0, 4 and 8 (Figure

15 1A, upper panel). P-specific IFN- $\gamma$ secreting $T$ cell response could be detected in

16 both lungs and spleens of P-KFD1 or P+CTB immunized mice (Figure 1B).

17 Meanwhile, high levels of P-specific saliva IgA, serum IgG and serum IgA antibody

18 responses could be induced by i.n. immunization with either P-KFD1 or P+CTB

19 compared to sham immunization (Figure 1C). These results indicated that recombinant $\mathrm{P}$ is immunogenic in mice by i.n. immunization in either P-KFD1 or

$\mathrm{P}+\mathrm{CTB}$ formulation, although the levels of $\mathrm{P}$-specific immune responses induced by

P-KFD1 were lower than P+CTB (Figures 1B and 1C). Next, the protective efficacy 
1 against RSV infection by i.n. immunization with P-KFD1 or P+CTB was evaluated

2 and compared with that by intramuscular (i.m.) immunization of formalin-inactivated

3 RSV (FI-RSV) in mice. Thus, one more group of mice was immunized with FI-RSV

4 at weeks 8 and 10 with Alum as adjuvant (Figure 1A, lower panel). All immunized

5 mice were challenged with RSV strain A2 at week 12, and sacrificed at 4 days post

6 challenge for evaluating viral loads in noses and lungs (Figure 1A). Compared with

7 control group, P-KFD1, P+CTB or FI-RSV immunized mice significantly reduced

8 viral loads in both noses and lungs (Figure 1D). In addition, viral loads decrease

9 could not be observed in either CTB only or KFD1 only intranasally immunized mice

(Figures 1E and 1F), suggesting that i.n. immunization of P-KFD1 or P+CTB

11 elicited P-specific immune responses conferred protection against RSV infection.

\section{Intranasal immunization with P-KFD1 protects mice against lung disease caused}

\section{by RSV infection}

A primary concern for development of an RSV vaccine is the potential for VED that occurred in FI-RSV vaccinated infants upon natural RSV infection. We thus evaluated the pathological changes in P-KFD1 or P+CTB immunized mice post RSV challenge. In contrast to the quick and massive body weight loss in FI-RSV immunized mice, body weight changes in P-KFD1 or $\mathrm{P}+\mathrm{CTB}$ immunized mice were not significantly different from those in saline group after RSV challenge (Figure S2A). We further evaluated the respiratory function of mice by testing their airway hyper-responsiveness (AHR). As shown in Figure 2A, P-KFD1 immunized mice had normal inhalation resistance $(\mathrm{Ri})$, exhalation resistance $(\mathrm{Re})$ and lung dynamic 
1 compliance (Cdyn) after challenge, which were similar to those measured parameters

2 in saline immunized mice and uninfected naïve mice. The FI-RSV immunized mice

3 showed dramatic increases of both $\mathrm{Ri}$ and Re, and significant decrease of Cdyn by

4 excitation with increasing concentrations of methacholine $(\mathrm{MCH})$. The $\mathrm{P}+\mathrm{CTB}$

5 immunized mice showed lower values of $\mathrm{Ri}$ and $\mathrm{Re}$ than the FI-RSV group, but

6 higher values than those of either the P-KFD1 or saline groups. These results

7 indicated that P-KFD1 intranasally immunized mice retained normal respiratory

8 function after RSV challenge, in contrast to FI-RSV immunized mice which showed

9 severe airway obstruction as reported in many studies (Knudson et al., 2015). In

10 parallel with the respiratory function, we observed lung histopathology changes by

11 H\&E and PAS staining at 8 days post RSV infection (dpi) in naïve or immunized

12 mice. As shown in Figure 2B, consistent with typical VED, overt inflammation and

13 mucus production (black arrows) were observed in lungs of FI-RSV immunized mice.

14 In contrast, neither inflammatory cell infiltration nor mucus secretion was observed in

15 lungs of P-KFD1 immunized mice (Figure 2B). It should be noted that more

16 inflammatory cell infiltration and mucus production were observed in the $\mathrm{P}+\mathrm{CTB}$

17 immunized mice compared to the P-KFD1 group, but less compared to the FI-RSV

18 group. In detail, the highest pathological scores of immunocyte aggregation around

19 both bronchioles and pulmonary vessels, and the highest score of interstitial

20 pneumonia were observed in FI-RSV immunized mice, while significant lower scores

21 were observed in the P-KFD1 or saline immunized mice (Figure 2C). The P+CTB

22 immunized mice showed lower scores of inflammations than the FI-RSV immunized 
1 mice, but higher scores than the P-KFD1 immunized mice. In addition, a significant

2 lower score of mucus production was observed in the P-KFD1 immunized mice

3 compared to that in either FI-RSV or P+CTB immunized mice (Figure 2D).

4 Furthermore, analysis of differential infiltrated immunocytes in lungs by flow

5 cytometry (FCM) showed an increase of eosinophils and T cells in the FI-RSV

6 immunized mice, and an increase of T cells in the P+CTB immunized mice, compared

7 to those of P-KFD1 or saline immunized mice upon RSV challenge (Figure 2E). We

8 also analyzed the Th bias in lungs of the immunized mice at 8 days after challenge by

9 ex-vivo PMA and ionomycin stimulation (Figure 2F). Compared to saline immunized mice, percentage of IL-4 secreting cells in $\mathrm{CD} 4^{+} \mathrm{T}$ cells increased significantly in

11 FI-RSV immunized mice as many studies previously reported (Knudson et al., 2015),

12 while no increase was observed in either the P-KFD1 or P+CTB immunized mice.

Moreover, there was no difference in frequency of $\mathrm{CD} 25^{+}$Foxp $3^{+}$Treg (Figure S2B) or IFN $-\gamma^{+} \mathrm{CD}^{+} \mathrm{T}$ cells among all groups of mice. It should be noted that a significant elevated percentage of IL-17A ${ }^{+} \mathrm{CD}^{+} \mathrm{T}$ cells was detected in $\mathrm{P}+\mathrm{CTB}$ immunized mice. In summary, in contrast to FI-RSV immunization, i.n. immunization with P-KFD1 rather than $\mathrm{P}+\mathrm{CTB}$ completely avoided occurrence of VED. Taken the anti-RSV efficacy in account (Figure 1D), P-KFD1 might be a potential safe and effective RSV vaccine candidate. 
1 strategy. We found that inoculation with $20 \mu \mathrm{g}$ of P-KFD1 provided better protection

2 against infection than with a dosage of $5 \mu \mathrm{g}$ or $1.25 \mu \mathrm{g}$ (Figure S3A), and boosting

3 twice provided better protection against infection than once (Figure S3B). Hence, the

4 protective efficacy of P-KFD1 i.n. immunization is dependent on both dosage of

5 immunogen and times of immunization. These results suggested that the degree of

6 immune responses induced by P-KFD1 i.n. immunization is correlated with protective

7 efficacy. Then we tried to elucidate, whether humoral immune response, or cellular

8 immune response, or both, mediated protection in P-KFD1 immunized mice.

Based on previous studies on the intracellular neutralization activities of anti-viral $\operatorname{IgA}$ in vitro and in vivo through $\mathrm{pIgR}$ mediated transcytosis (Burns et al., 1996; Yang et al., 2020; Zhou et al., 2019; Zhou et al., 2011), P-KFD1 i.n. immunization was performed in wild type mice, as well as pIgR knockout mice $\left(\mathrm{pIgR}^{-/-}\right)$, to test if P-specific secretory IgA plays a role or not. In line with reported data (Asahi et al., 2002; Shimada et al., 1999), our results showed IgA antibodies accumulated in serum, but could not actively be transported to the mucosal surface by the lack of pIgR (Figure S3C). In parallel, P-KFD1 i.n. immunization induced lower level of P-specific serum $\operatorname{IgG}$, but higher level of serum IgA and undetectable P-specific saliva $\operatorname{IgA}$ in $\mathrm{pIgR}^{-/-}$mice compared to those in wild type mice (Figure $3 \mathrm{~A}$ ). Despite the striking difference in P-specific secreting antibody response, the protection provided by P-KFD1 i.n. immunization against RSV infection in both noses and lungs of $\mathrm{pIgR}^{-/-}$mice was as similar as that of wild type mice (Figure 3B).

This result suggested that $\mathrm{P}$-specific mucosal IgA antibodies did not mediate the 
1 protection against $\mathrm{RSV}$ by intraepithelial neutralization related to $\mathrm{pIgR}$. We then

2 performed anti-serum transfer experiment and found no anti-viral efficacy could be

3 conferred to naïve recipient mice by transfer of serum from the P-KFD1 immunized

4 mice (Figure 3C). It suggested that P-specific antibodies in serum were not the main

5 protective factors. Collectively, P-specific humoral immune response induced by

6 P-KFD1 i.n. immunization does not appear to be the main mediator for protection

7 against RSV infection.

Thus, we speculated that the $\mathrm{T}$ cell response induced by P-KFD1 i.n. immunization do mediate protection. As showed in Figures 1B and S3D, P-KFD1 i.n. immunization induced P-specific IFN- $\gamma$, IL-17A but not IL-4 secreting $\mathrm{T}$ cell responses. P-specific IFN- $\gamma$ secreting T cells could be detected upon stimulation with $\mathrm{P}$ in both lungs and spleens at day 7 post second boost immunization $(8 w+7 d)$, decreasing to nearly undetectable levels thereafter $(8 w+28 d)$, but starting to rebound after challenge at $1 \mathrm{dpi}(12 \mathrm{w}+1 \mathrm{~d})$ and increasing to a still higher level at $4 \mathrm{dpi}$ $(12 w+4 d)$ (Figure 3D). Accordingly, after challenge, the virus replicated only from $1 \times 10^{3}$ at 1 dpi to $1.5 \times 10^{3}$ at 4 dpi in lungs of P-KFD1 immunized mice, but replicated dramatically from $0.5 \times 10^{3}$ at 1 dpi to $1 \times 10^{5}$ at 4 dpi in lungs of saline immunized mice (Figure S3E). This delayed anti-virus effect implied that $\mathrm{T}$ cells might take part in the protection conferred by P-KFD1 i.n. immunization. With regard to IFN- $\gamma$ production by purified $\mathrm{CD} 4^{+}$or $\mathrm{CD}^{+} \mathrm{T}$ cells, $\mathrm{P}-\mathrm{KFD} 1$ i.n. immunization induced much higher fraction of P-specific IFN- $\gamma$ producing $\mathrm{CD}^{+} \mathrm{T}$ cells than the fraction of

P-specific IFN- $\gamma$ producing $\mathrm{CD}^{+} \mathrm{T}$ cells (Figure 3E). This indicated that the 
$1 \quad$ P-specific $\mathrm{CD}^{+} \mathrm{T}$ cells elicited by P-KFD1 i.n. immunization should be the main

2 cellular source of IFN- $\gamma$.

To confirm the role of $\mathrm{T}$ cells played in the protection against infection, $\mathrm{CD} 4^{+}$ and/or $\mathrm{CD}^{+} \mathrm{T}$ cells were depleted in vivo by using anti-CD4-specific and/or anti-CD8-specific antibodies (Figure S3F). When $\mathrm{T}$ cells were depleted simultaneously with anti-CD4 and anti-CD8 antibody together ( $\alpha$-CD4 $+\alpha$-CD8), the anti-viral activity in P-KFD1 immunized mice was abrogated in both noses and lungs (Figure 3F). When only $\mathrm{CD} 4^{+} \mathrm{T}$ cells were depleted, the anti-viral efficacy in P-KFD1 immunized mice declined significantly to the same level as that in saline immunized mice. However, if only $\mathrm{CD}^{+} \mathrm{T}$ cells were depleted, anti-viral efficacy remained intact in both noses and lungs (Figure 3F). Hence, the protection against RSV conferred by i.n. immunization with P-KFD1 was mainly $\mathrm{CD}^{+} \mathrm{T}$ cell dependent.

\section{Both local and peripheral $\mathrm{CD4}^{+} \mathrm{T}$ cells play roles in protection against $\mathrm{RSV}$}

\section{infection}

Considering the importance of local immunity for protection against RSV infection in the upper respiratory tract and lung, we further investigated whether the protective $\mathrm{CD} 4^{+} \mathrm{T}$ cells resided in respiratory tract or migrated from lymphoid organ. To make this determination, a sphingosine-1-phosphate receptor 1 agonist, FTY720, was adopted for blocking the egress of $\mathrm{T}$ lymphocytes from lymphoid organs of experimental mice (Brinkmann et al., 2002; Mandala et al., 2002). As shown in Figure 4A, FTY720 treatment did not affect the number of P-specific IFN- $\gamma$ 
1 producing $\mathrm{T}$ cells in spleens of P-KFD1 immunized mice, but rather decreased those

2 in lungs significantly from about 200 to $70 \mathrm{SFC} / 10^{6}$ lymphocytes. This result

3 indicated that in lung post infection, more than half of the P-specific IFN- $\gamma$ producing

$4 \quad$ T cells migrated from lymphoid organs, and could be blocked by FTY720 treatment.

5 Consistent with the decreased migration of T cells, the anti-viral efficacy of P-KFD1

6 immunized mice was mitigated by the FTY720 treatment, while no distinguishable

7 difference was observed in saline immunized mice, irrespective of FTY720 treatment

8 (Figure 4B). This suggested circulating $\mathrm{T}$ cells took part in protection afforded by

9 P-KFD1 i.n. immunization. Meanwhile, FTY720 treatment just partially abrogated the anti-viral efficacy of the P-KFD1 immunized mice, in which viral titers in both noses and lungs were still significantly lower than those of the saline immunized mice, also treated with FTY720 (Figure 4B), further demonstrating that resident T cells in the lungs also played a protective role in P-KFD1 i.n. immunization. On the other hand, compared with i.n. immunization, intraperitoneal (i.p.) immunization with P-KFD1 induced comparable levels of P-specific IFN- $\gamma^{+} \mathrm{T}$ cell response and production of IFN- $\gamma$ in the spleen, but lower levels in lung (Figure S4). In addition, i.p. immunization with P-KFD1 resulted in significantly reduced viral load in lung, but not in nose (Figure 4C). Taken together, both the migrated $\mathrm{T}$ cells from lymphoid organ and the resident $\mathrm{T}$ cells in the respiratory tract contributed to local in situ anti-viral immunity in P-KFD1 immunized mice.

To further verify that it was $\mathrm{CD}^{+}{ }^{+} \mathrm{T}$ cells evoked by P-KFD1 immunization that directly contributed to protection against viral infection, we performed adoptive 
1 transfer experiments. Briefly, $\mathrm{CD}^{+} \mathrm{T}$ cells from the spleens of intraperitoneally or

2 intranasally immunized mice were sorted by antibody-conjugated microbeads and

3 then transferred into naïve mice prior to RSV challenge. Mice that received $\mathrm{CD}^{+}{ }^{+} \mathrm{T}$

4 cells from P-KFD1 intraperitoneally immunized donors had lower viral loads in both

5 noses and lungs post challenge (Figure 4D). Mice that received $\mathrm{CD}^{+} \mathrm{T}$ cells from

$6 \quad$ P-KFD1 intranasally immunized mice also exhibited lower viral load in lungs, but

7 only marginally lower viral titer in the noses (Figure 4E). Collectively, these data

8 suggested that the P-specific $\mathrm{CD}^{+} \mathrm{T}$ cells induced by P-KFD1 i.n. immunization,

9 either resided in, or migrated to the respiratory tract, played key protective roles 10 against RSV infection.

11 Sc-RNA seq reveals a cluster of specific Th17 cells corresponding to the P-KFD1

\section{i.n. immunization}

Next, we tried to directly investigate the $\mathrm{CD}^{+} \mathrm{T}$ cell responses elicited by P-KFD1 i.n. immunization during the acute phase of RSV infection by sc-RNA seq (single cell RNA sequencing). As cell surface integrin molecules CD11a and CD49d can be used to distinguish antigen-experienced $\mathrm{CD} 4^{+} \mathrm{T}$ cells and naïve $\mathrm{CD} 4^{+} \mathrm{T}$ cells (Knudson et al., 2014; McDermott and Varga, 2011), we sorted the antigen-experienced CD11a $\mathrm{a}^{\text {high }}$ $\mathrm{CD} 4^{+} \mathrm{T}$ cell subset and antigen-unexperienced $\mathrm{CD} 11 \mathrm{a}^{\text {low }} \mathrm{CD} 49 \mathrm{~d}^{-} \mathrm{CD} 4^{+} \mathrm{T}$ cell subset from lungs of saline or P-KFD1 intranasally immunized mice on 4 dpi by FACS (Figures 5A and S5A). As expected, P-specific IFN- $\gamma^{+} \mathrm{CD}^{+}$and $\mathrm{IL}-17 \mathrm{~A}^{+} \mathrm{CD} 4^{+} \mathrm{T}$ cell responses could only be detected in the CD11 $\mathrm{a}^{\text {high }} \mathrm{CD} 4^{+} \mathrm{T}$ cell subsets of P-KFD1 immunized mice (Figure S5B). To focus on these responsive CD11a ${ }^{\text {high }}$ cells in the 
$1 \mathrm{CD}^{+} \mathrm{T}$ cells, we mixed the sorted $\mathrm{CD} 11 \mathrm{a}^{\text {high }}$ subset with hashtag antibody labeled

2 sorted CD11 $\mathrm{a}^{\text {low }} \mathrm{CD} 49 \mathrm{~d}^{-}$cell subset at a ratio of approximately 5:3, before performing

3 sc-RNA seq of the transcriptome profile and TCR repertoire of $\mathrm{CD} 4^{+} \mathrm{T}$ cells (Figure

4 5B). Unsupervised hierarchical clustering and t-distributed stochastic neighbor

5 embedding (t-SNE) dimensional reduction analysis based on the transcriptomes of

6 pooled samples identified fifteen $\mathrm{CD} 4^{+} \mathrm{T}$ cell clusters (Figures $\mathbf{5 C}$ and $\mathbf{S 5 C}$ ). The

7 cells in clusters 1,3 and 7 were naïve-like $\mathrm{CD}^{+} \mathrm{T}$ cells, since they expressed

8 transcripts of Ccr7, Lefl and Igfbp4 (Figures 5D and S5E). Cells in cluster 0 highly

9 expressed transcripts of Itgb1, Cd40lg, Il2, and Ifng, which resembled effector

10 memory or tissue resident memory $\mathrm{CD}^{+} \mathrm{T}$ cells $(\mathrm{Tem} / \mathrm{Trm})($ Figure $5 \mathrm{D})$. Whereas,

11 cluster 4 cells highly expressed transcripts of Il2ra, Foxp3 and Ikzf2 which seemed

like Treg cells. Notably, cluster 6 cells were enriched in Il17a, Ill7f, Ccr6 and Rorc,

indicative of Th17 subset (Figure 5D). Other clusters were also designated based on

the signature genes expression (Figure 5D). Moreover, sc-RNA seq revealed a significantly higher proportion of Th17 cells in P-KFD1 induced CD4 ${ }^{+} \mathrm{T}$ cells compared to saline group (Figure 5C).

As expected, the hashtag labeled antigen-unexperienced CD11a ${ }^{\text {low }} \mathrm{CD} 49 \mathrm{~d}^{-} \mathrm{CD} 4^{+}$

T cells were mainly located in the naïve-like clusters 1,3 and 7 cells (Figures $\mathbf{5 C}$ and

S5D), and showed genes expression pattern similar as naïve $\mathrm{CD} 4^{+} \mathrm{T}$ cells (Figure

S5E). Moreover, similar as that in the naïve-like cells, differential expression genes

(DEGs, $\log _{2}|\mathrm{FC}|>1, \mathrm{P}<0.05$ ) were rarely found in hashtag ${ }^{+}$cells between $\mathrm{P}-\mathrm{KFD} 1$ 
1 genes) could be identified in the non-naïve cells that excluded clusters 1, 3 and 7 in

2 P-KFD1 group compared to saline group (Figure 5E). David analysis revealed that

3 the upregulated DEGs in P-KFD1 group were enriched in two KEGG pathways

4 "cytokine-cytokine receptor interaction" and "inflammatory bowel disease", and in

5 two Gene Ontology (GO) biology processes "inflammatory response" and "immune

6 response" in P-KFD1 group (Figure 5F). The representative DEGs included Th17

7 marker genes $I l 17 a$, Ill7f, Rorc, Ccr6, activation related marker genes Il2ra, Cxcr6,

8 and cytotoxicity-associated genes Lta etc. (Figures 5G and S5G).

Then we aimed at the set of $\mathrm{T}$ cells with the same TCRs, which were the sequencing identified clonal expanded $\mathrm{CD}^{+} \mathrm{T}$ cells. TCR sequencing totally identified 5695 and 5769 barcodes in saline group and P-KFD1 group, respectively. It is obviously that the frequency and the number of T cells with repeatedly used TCRs in P-KFD1 group (625) were much higher than that in saline group (330) (Figures 6A, S6A and S6B). Moreover, the clone sizes of $\mathrm{CD}^{+} \mathrm{T}$ cells in P-KFD1 group were much larger than that in saline group (Figure 6B). In addition, in P-KFD1 group, a large portion of the $\mathrm{CD} 4^{+} \mathrm{T}$ cells with repeatedly used TCRs were located in cluster 6 Th17 cells. These suggested epitope-specific $\mathrm{CD}^{+} \mathrm{T}$ cell responses especially the Th17 cells were elicited by P-KFD1 i.n. immunization. Consistently, between saline group and P-KFD1 group, TCR usage in the non-naïve $\mathrm{CD}^{+} \mathrm{T}$ cells that excluded clusters $1,3,7$ or cells with repeatedly used TCRs were significantly different (Figures S6C and S6D). In CD4 ${ }^{+} \mathrm{T}$ cells with repeatedly used TCRs, large amount of DEGs existed between P-KFD1 group versus saline group (Figure 6C). These upregulated 
1 genes in P-KFD1 group also included Th17 related transcripts of genes $(C c r 6, I l 17 a$,

$2 I l l 7 f$ and $I l 23 r$ ), activation related genes such as Il2ra and Cxcr6, as well as some

3 immune response-associated genes such as Ccr1, Csfl, Lta, Illr1 and Tnfsf11

4 (Figures 6D and S6E). The results above all suggested that P-KFD1 i.n.

5 immunization induced expansion and activation of Th17 cells on 4 dpi at 6 transcriptional level.

ELISpot assay of pulmonary immunocytes showed that much higher levels of P-specific IL-17A ${ }^{+} \mathrm{T}$ cell response were elicited in P-KFD1 intranasally immunized mice on 4 days after RSV challenge (Figure 6E). Generally, P-KFD1 i.n. immunization boosted P-specific Th17 immune responses.

\section{P-specific IL-17A cooperates with IFN- $\gamma$ in resisting RSV infection}

Then, transfer model was adopted to further confirm the characteristics of $\mathrm{CD}^{+} \mathrm{T}$ cell responses induced by P-KFD1 i.n. immunization. Briefly, splenocytes prepared from P-KFD1, KFD1 or saline intranasally immunized mice were labeled with carboxyfluorescein succinimidyl ester (CFSE) and intravascularly injected into naïve mice at 12 hours prior to RSV challenge respectively. Lymphocytes in lungs and spleens of the recipient mice were isolated at 4 days post challenge and analyzed by FCM (Figure 7A). The CFSE-labeled cells derived from donor mice could be detected and differentiated as un-proliferated $\mathrm{CFSE}^{\text {high }}$ cells and proliferated CFSE ${ }^{\text {low }}$ cells (Figure 7B). As depicted in Figure 7C, in the $\mathrm{CFSE}^{+}$cells, percentages of $\mathrm{CFSE}^{\text {low }} \mathrm{CD}^{+} \mathrm{T}$ cells from P-KFD1 immunized mice were significantly higher than those from KFD1 or saline immunized donors, in both lungs and spleens of the 
1 recipient mice, but $\mathrm{CFSE}^{\text {low }} \mathrm{CD}^{+} \mathrm{T}$ cells were not. This result indicated that

2 P-specific $\mathrm{CD}^{+} \mathrm{T}$ cells induced by P-KFD1 i.n. immunization could expand upon

3 RSV challenge.

In order to detect potential atopy of Th responses, lymphocytes of the recipient mice were stimulated by PMA and ionomycin ex vivo and analyzed. The percentages of IFN- $\gamma^{+}$cells, $\mathrm{IL}_{-17 \mathrm{~A}^{+}}$cells or $\mathrm{IL}_{-} 4^{+}$cells in $\mathrm{CFSE}^{-} \mathrm{CD}^{+} \mathrm{T}$ cells did not differ among the three different recipient groups in lungs and spleens, respectively, suggesting that adoptive transfer did not change Th bias of recipient mice after RSV challenge (Figures 7D and 7E, hollow column). In $\mathrm{CFSE}^{+} \mathrm{CD}^{+} \mathrm{T}$ cells, both the percentages of IFN- $\gamma^{+}$cells and IL- $17 \mathrm{~A}^{+}$cells from P-KFD1 immunized donors were significantly higher than those from saline immunized donors, in lungs and spleens of recipients respectively. Whereas, no differences were found in percentages of $\mathrm{CFSE}^{+}$ IL- $4^{+} \mathrm{CD} 4^{+} \mathrm{T}$ cells among all groups (Figures 7D and 7E, solid column). These results indicated P-KFD1 i.n. immunization induced both Th1 and Th17 responses at 4 dpi. We also found that the percentages of $\mathrm{CFSE}^{+} \mathrm{IFN}_{-} \gamma^{+} \mathrm{CD}^{+} \mathrm{T}$ cells from P-KFD1 intranasally immunized donors were slightly higher than those from saline

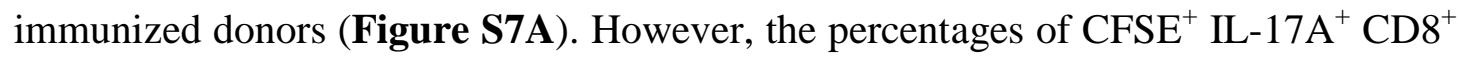
T cells were all at low levels and showed no difference among the recipients (Figure S7A).

Furthermore, the percentages of $\mathrm{CFSE}^{+} \mathrm{IFN} \gamma^{+} \mathrm{CD}^{+} \mathrm{T}$ cells, $\mathrm{CFSE}^{+} \mathrm{IL}_{-17 \mathrm{~A}^{+}}$ $\mathrm{CD}^{+} \mathrm{T}$ cells (Figure 7D) and $\mathrm{CFSE}^{+} \mathrm{IFN}_{-} \gamma^{+} \mathrm{CD}^{+} \mathrm{T}$ cells (Figure S7A) from P-KFD1 immunized donors were higher than those from KFD1 immunized mice. 
1 These results implied that P-KFD1 i.n. immunization induced P-specific Th1 and

2 Th17 responses, as well as IFN $-\gamma^{+} \mathrm{CD}^{+} \mathrm{T}$ cell response, especially in RSV infected

3 tissue. When the same CFSE labeling and adoptive transfer experiments were

4 performed for the FI-RSV and P+CTB immunized mice, a dramatically higher level

5 of $\mathrm{CD}^{+} \mathrm{T}$ cell proliferation at 4 dpi could be observed compared to that of P-KFD1

6 immunized mice (Figure S7B). Besides, a robust Th2-biased response in the FI-RSV

7 immunized mice and a robust Th17-biased immune response in the $\mathrm{P}+\mathrm{CTB}$

$8 \quad$ immunized mice could be observed in both lungs and spleens, respectively (Figure

9 S7C), which were also consistent with the results in Figure 2F.

To determine whether the Th1 and/or Th17 responses mediated anti-viral

11 efficacy in P-KFD1 intranasally immunized mice, antibodies against IFN- $\gamma(\alpha-$ IFN- $\gamma)$ and/or IL-17A ( $\alpha$-IL-17A) were injected into the P-KFD1 immunized mice during RSV infection, respectively. As shown in Figure 7F, simultaneous administration of both anti-IFN- $\gamma$ and anti-IL-17A antibodies could abolish anti-viral efficacy in both noses and lungs of P-KFD1 intranasally immunized mice. In contrast, administration of only anti-IFN- $\gamma$ antibody or anti-IL-17A antibody could not abrogate anti-viral efficacy; instead, significantly lower viral loads were retained in both noses and lungs of P-KFD1 intranasally immunized mice compared to those of saline immunized mice, respectively. These data suggested that T cell-derived IFN- $\gamma$ or IL-17A alone could mediate the inhibition of RSV replication in vivo. Taken together, P-KFD1 i.n.

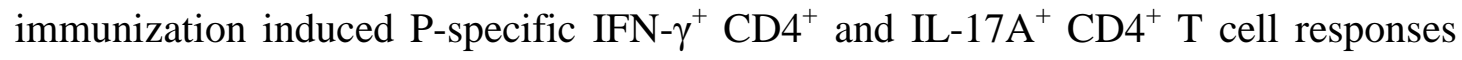


1 without changing Th bias, and provided protection against RSV infection depended

2 on IFN- $\gamma$ or IL-17A.

\section{DISCUSSION}

4 In past decades, many efforts and resources have been devoted to the development of

5 a safe and efficacious RSV vaccine to prevent infection by this respiratory pathogen.

6 However, the fact that 1) natural RSV infection does not elicit long-lasting immunity

7 and 2) repeated infections occur throughout life (Glezen et al., 1986; Henderson et al.,

8 1979) results in a dilemma for investigators designing a vaccination strategy by

9 mimicking the host immune response, following natural infection with RSV.

10 Furthermore, VED triggered by immunization with FI-RSV has presented yet another

11 major obstacle against the development of an RSV vaccine (Kapikian et al., 1969;

12 Kim et al., 1969).

13 Here, we reported how we used new strategies to develop a safe and effective mucosal RSV vaccine targeting an internal RSV antigen $\mathrm{P}$ that has been seldom investigated. And we examined the immune responses in relation to virological and pathological features of the fusion protein P-KFD1 intranasally immunized animals before and after RSV challenge by comparison with those immunized with $\mathrm{P}+\mathrm{CTB}$ or

FI-RSV. Our data showed that P-KFD1 i.n. immunization induces P-specific immune responses and inhibits RSV replication in both the upper and lower respiratory tract of mice. It is noteworthy that P-KFD1 i.n. immunization does not result in VED, whereas $\mathrm{P}+\mathrm{CTB}$ i.n. immunization do cause some enhanced respiratory disease (ERD) 
1 which is different from the typical VED featured by the infiltration of eosinophils and

2 highly Th2-biased immune response in FI-RSV immunized mice.

As part of our initial hypothesis, P-specific secreted IgA response in P-KFD1 immunized mice would play a role in prevention against viral infection. However, neither P-specific secreted IgA nor P-specific serum was found to be relevant to protection against RSV infection in our immunization regimen, though our experiments performed with $\mathrm{pIgR}^{-/-}$mice, or by serum transfer, could not completely exclude the possible roles of antibodies or B cells through other unknown mechanisms.

We thus analyzed the kinetics of $\mathrm{T}$ cell response associated with P-KFD1 i.n. immunization and RSV challenge. We demonstrated that P-specific $\mathrm{CD}^{+} \mathrm{T}$ cells, either in lung or spleen, induced by P-KFD1 i.n. immunization played a central role in the protection against RSV infection. Our finding on the protective relevance of the RSV P-specific $\mathrm{CD}^{+} \mathrm{T}$ cells in mouse model is in line with the preexisting influenza-specific memory $\mathrm{CD} 4^{+} \mathrm{T}$ cells in blood, which were found to be correlated with disease protection against influenza challenge in humans (Wilkinson et al., 2012). Studies on influenza and coronavirus further showed the antigen-specific $\mathrm{CD}^{+} \mathrm{T}$ cells can resist infection by releasing IFN- $\gamma$ (McKinstry et al., 2012; Zhao et al., 2016). A subcutaneous immunization with recombinant BCG strain expressing RSV N could also induce protective Th1-type immunity against RSV infection in mice (Bueno et al., 2008; Cautivo et al., 2010). These previous studies further support our finding on the 
1 protective role of $\mathrm{P}$-specific Th1 immune response induced by P-KFD1 i.n.

2 immunization.

The role of Th17 response remains controversial in different circumstances. A growing body of evidence indicates that Th17 cells play an important role in resisting some bacterial and fungal infections (Bacher et al., 2019; Li et al., 2018; Shao et al., 2019). An influenza virus vaccine candidate, termed CTA1-3M2e-DD, induced M2e-specifc memory $\mathrm{CD}^{+} \mathrm{T}$ cells that protected against infection also in an IL-17-dependent manner (Eliasson et al., 2018). However, the Th17 immune response is usually considered pathogenic by the tendency to exacerbate inflammatory response, which is closely related to several diseases, such as chronic obstructive pulmonary disease, cystic fibrosis and asthma (Iwanaga and Kolls, 2019). IL-17 produced during RSV infection has also been reported to be involved in increasing mucus secretion (Mukherjee et al., 2011). With the help of sc-RNA seq, we clearly identified the Th17 expansion in P-KFD1 intranasally immunized mice post infection. Moreover, besides Th17 representative genes (such as Rorc, Ccr6, Ill7a and Ill7f) and activation related genes (such as Il2ra and Cxcr6), some cytotoxicity-associated genes such as Lta, and Tnfsfl1 were also significantly upregulated. Future investigation to determine whether these cytotoxicity-associated genes contribute to the protection against RSV infection is warranted. In our adoptive transfer experiments, both Th1 and Th17 immune responses were detected in the $\mathrm{P}-\mathrm{KFD} 1$ and $\mathrm{P}+\mathrm{CTB}$ groups, but the magnitude of Th17 immune response in the $\mathrm{P}+\mathrm{CTB}$ group was much higher than that in the P-KFD1 group. A kind of aberrant Th17 response might explain why impaired 
1 respiratory function, inflammatory cell infiltration and mucus production occurred in

2 the P+CTB immunized and RSV challenged mice. The underlying mechanism also

3 needs further investigation.

Th1-related immune responses may also contribute to immunopathological damage during respiratory virus infection under some circumstances (Knudson et al., 2015; Wimalasundera et al., 1997). For any candidate RSV vaccine, safety is as

7 important as effectiveness. In this study, P-KFD1 i.n. immunization induced moderate

8 P-specific Th1 and Th17 immune responses without affecting Th bias, which might

9 be involved in averting adverse effects. Although subunit vaccines are not the strongest vaccine format to induce $\mathrm{T}$ cell responses, i.n. immunization with P-KFD1 did induce $\mathrm{T}$ cell responses in a manner that struck a balance between safety and effectiveness in the typical RSV infection mouse model. Using other immunization strategies to elevate the magnitude of $\mathrm{T}$ cell responses might, however, change $\mathrm{Th}$ bias and induce ERD, such as the symptoms that appeared in $\mathrm{P}+\mathrm{CTB}$ immunized mice, as discussed above. RSV replication. BALB/c mice infected with commonly used laboratory RSV strains, including the A2 strain we used, do not exhibit high viral loads or pulmonary mucus (Meng et al., 2014). Nevertheless, either viral load or pulmonary mucus production was measurable for comparatively evaluating both anti-viral efficacy and immunopathology in the mice subjected to different vaccinations in our study. 
1 immunized mice were characterized, the detail protective mechanism remains elusive.

2 Further investigation on the mechanism and function of Th17 response during RSV

3 infection is warranted to strike an optimal balance between anti-viral activity and

4 immunopathology. Finally, we asked if P-specific T cell responses could be boosted

5 to afford greater protection against RSV infection in human beings, even though

6 researchers (Guvenel et al., 2020) have already detected P-specific T cell responses in

7 peripheral blood of healthy adults under experimental RSV inoculation.

In summary, our study provides a new concept for RSV vaccine development, taking into account a balanced $\mathrm{Th} 1 / \mathrm{Th} 17 \mathrm{CD}^{+} \mathrm{T}$ cell response for evaluation of an RSV vaccine. This concept is exemplified by P-KFD1 i.n. immunization that generated RSV P-specific $\mathrm{CD}^{+} \mathrm{T}$ cell responses and conferred protection against RSV infection and disease in mice. Overall, the E. coli-produced recombinant flagellin-phosphoprotein can prevent RSV infection without raising any VED concerns.

\section{ACKNOWLEDGMENTS}

We thank Professor Zishu Pan at Wuhan University for providing RSV strain A2, and Professor $\mathrm{Xu}$ Yang at Central China Normal University for technical assistance in detecting airway responsiveness of mice. We thank Xuefang An, Li Li, He Zhao, Dr. Ding Gao and Juan Min at the core facility and technical support of Wuhan Institute of Virology, CAS, for their kind help in animal experiments and flow cytometry analysis. We are grateful to Yan Wang for assistance in cell sorting by FACS at Institute of Hydrobiology, CAS. We are also grateful to Dr. Yuan Liu and Rulei Yin 
1 at Beijing Emei Tongde Technology Development Co., Ltd for their generous support

2 in single cell RNA sequencing and transcriptome analysis. This work was supported

3 by the National Natural Science Foundation of China (No. 31970878) and the

4 "One-Three-Five" Strategic Planning Program of Wuhan Institute of Virology, CAS

5 (No. Y206515SA1).

6 AUTHOR CONTRIBUTIONS

$7 \quad$ B. Z. and J. Y. designed and conducted the experiments, analyzed the data and drafted

8 the manuscript. B. H. and S. L. provided assistance in sc-RNA seq data analysis. X. L.,

9 H. Y., Y. Y., B. L., F. Z., X. F. and Y. Z. provided assistance in animal experiments.

D. Z., Y. C., M. Z. and E. Z. contributed to discussion and designment of animal

11 studies. S. J. and H. Yan conceived and supervised the work, designed the experiments, analyzed the data, wrote and revised the manuscript.

\section{DECLARATION OF INTERESTS}

H. Yan., J. Y., and B. Z. are inventors on a patent entitled "Respiratory Syncytial

Virus vaccine" (US 10,232,033 B2; Japan 6655736; Korea 10-2102065; and pending applications in China, Singapore and European Union). The patent right was assigned competing interests. 


\section{FIGURES LEGENDS}

2 Figure 1. P-specific immune responses induced by intranasal immunization with

3 P-KFD1 or P+CTB protect mice against RSV infection. (A) Immunization

4 schedule. Groups of BALB/c mice were immunized with saline, P+CTB, P-KFD1 or

$5 \quad$ FI-RSV at indicated time points, respectively, prior to infection with $2 \times 10^{6} \mathrm{PFU}$ of

6 RSV A2 and sacrificed at 4 days post RSV infection (dpi). (B) P-specific IFN- $\gamma$

7 secreting $\mathrm{T}$ cells were determined by ELISpot and were expressed as IFN- $\gamma^{+}$spot

8 forming cells (SFC)/ million cells at 7 days post last immunization, $\mathrm{n}=5$ mice per

9 group. (C) P-specific saliva IgA, serum IgG and serum IgA antibody titers in P+CTB or P-KFD1 immunized mice were determined by ELISA at 14 days post last

11 immunization, $\mathrm{n}=6$ mice per group. (D) RSV titers in saline, FI-RSV, P+CTB or P-KFD1 immunized mice were monitored at 4 dpi, $\mathrm{n}=6$ mice per group. (E) RSV titers in saline, $\mathrm{CTB}$ or $\mathrm{P}+\mathrm{CTB}$ immunized mice were measured at $4 \mathrm{dpi}, \mathrm{n}=5$ mice per group. (F) RSV titers in saline, KFD1 or P-KFD1 immunized mice were detected at $4 \mathrm{dpi}, \mathrm{n}=5$ mice per group. Data are represented as mean $\pm \mathrm{SEM}$ of three independent experiments. In Figure 1B, two columns were compared using unpaired $t$ test. In Figures 1C to 1F, groups were compared using one-way ANOVA. * p $<0.05$, 
2 Figure 2. Intranasal immunization with P-KFD1 protects mice against lung

3 disease caused by RSV infection. Groups of BALB/c mice were immunized with

4 saline, FI-RSV, P+CTB or P-KFD1, respectively, prior to RSV challenge, and

$5 \quad$ sacrificed on 8 dpi. (A) Inspiratory resistance, expiratory resistance and lung dynamic

6 compliance of mice were monitored, $\mathrm{n}=5$ mice per group. (B) Hematoxylin and

7 eosin (H\&E) and periodic acid-Schiff (PAS) staining were performed on lung sections.

8 (C) Pathological scores of immunocytes aggregation around bronchioles, pulmonary

9 vessels and scores of interstitial pneumonias were evaluated according to the

10 H\&E-stained sections, $\mathrm{n}=5$ mice per group. (D) Scores of mucus production were

11 evaluated according to the PAS-stained sections, $\mathrm{n}=5$ mice per group. (E) Numbers

12 of eosinophils and T lymphocytes in lungs of mice were assessed by flow cytometry

13 (FCM), $\mathrm{n}=5$ mice per group. (F) Percentages of $\mathrm{IL}-4^{+}, \mathrm{IL}-17 \mathrm{~A}^{+}$or IFN- $\gamma^{+}$cells in

$14 \mathrm{CD}^{+} \mathrm{T}$ cells with PMA and ionomycin stimulation in lungs of mice were determined

15 by $\mathrm{FCM}, \mathrm{n}=5$ mice per group. Data are represented as mean \pm SEM of two

16 independent experiments. In Figure $\mathbf{2 A}$, groups were compared using regular

17 two-way ANOVA with saline group. In Figures $2 \mathbf{C}$ to $\mathbf{2 F}$, groups were compared

18 using one-way ANOVA. * $\mathrm{p}<0.05$, ** $\mathrm{p}<0.01$, *** $\mathrm{p}<0.001$, ns means

19 non-significant. See also Figure S2. 
2 Figure 3. $\mathrm{CD4}^{+} \mathrm{T}$ cells but not antibodies provide protection against $\mathrm{RSV}$

3 infection. (A) P-specific antibody responses in P-KFD1 immunized $\mathrm{pIgR}^{-/-}$mice were

4 measured at 14 days post last immunization, $n=6$ mice per group. (B) Viral loads in

5 saline or P-KFD1 immunized $\operatorname{pIgR}^{-/-}$and wild type mice were measured on 4 dpi, $\mathrm{n}=$

66 mice per group. (C) RSV titers in recipient mice that received immune sera from

7 saline, FI-RSV or P-KFD1 immunized mice before RSV challenge, were monitored

8 on 4 dpi, $\mathrm{n}=5 \sim 6$ mice per group. (D) $\mathrm{P}$-specific IFN- $\gamma^{+} \mathrm{T}$ cell responses were

9 determined by ELISpot at indicated time points, $\mathrm{n}=5$ mice per group. (E) P-specific IFN- $\gamma^{+}$responses of purified splenic $\mathrm{CD} 4^{+} \mathrm{T}$ cells and $\mathrm{CD} 8^{+} \mathrm{T}$ cells were detected by ELISpot on 7 days post last immunization, $\mathrm{n}=4$ replicates per group. (F) RSV titers in saline or P-KFD1 intranasally immunized mice that were treated with depletion antibodies against $\mathrm{CD} 4^{+}$and/or $\mathrm{CD}^{+} \mathrm{T}$ cells were detected on $4 \mathrm{dpi}, \mathrm{n}=5 \sim 6$ mice per group. Data are represented as mean \pm SEM of two independent experiments. In Figures $\mathbf{3 A}$ and 3B, two groups were compared using un-paired t test. In Figure 3C, compared using regular two-way ANOVA. $* \mathrm{p}<0.05, * * \mathrm{p}<0.01, * * * \mathrm{p}<0.001$, ns means non-significant. See also Figure S3. 
1 Figure 4. Both local and peripheral $\mathrm{CD4}^{+} \mathrm{T}$ cells play roles in protection

2 against RSV infection. (A and B) Saline or P-KFD1 intranasally immunized mice

3 were intraperitoneally injected with vehicle or FTY720 daily on 7 successive days. (A)

$4 \quad$ P-specific IFN- $\gamma^{+}$T cell response in lungs and spleens $(\mathrm{n}=10$ mice per group) and (B)

$5 \quad$ RSV titers in noses and lungs of mice ( $n=5$ mice per group) were detected at 4 dpi.

6 (C) Mice were intranasally or intraperitoneally immunized with P-KFD1 at four-week

7 intervals three times prior to RSV challenge. RSV titers in noses and lungs were

8 determined at 4 dpi, $n=8$ mice per group. (D and E) Splenic CD4 ${ }^{+} \mathrm{T}$ cells were

9 sorted by microbeads from saline or P-KFD1 immunized mice and were

10 intravascularly injected into naïve mice, respectively, followed by RSV challenge.

11 Viral loads in noses and lungs of recipients that received $\mathrm{CD}^{+} \mathrm{T}$ cells from

12 intraperitoneally immunized donors (D) or from intranasally immunized donors (E)

13 were detected at 4 dpi, $n=6$ mice per group. Data are represented as mean \pm SEM of

14 two pooled experiments for Figures 4A and 4C. Data are represented as mean \pm

15 SEM of two independent experiments for Figures 4B, 4D and 4E. In Figure 4A,

16 groups were compared using regular two-way ANOVA. In Figures $4 B$ to $4 E$, groups

17 were compared using one-way ANOVA. * $\mathrm{p}<0.05$, ** $\mathrm{p}<0.01$, *** $\mathrm{p}<0.001$, ns 18 means non-significant. See also Figure S4. 
2 Figure 5. Sc-RNA seq of $\mathrm{CD4}^{+} \mathrm{T}$ cells reveals the elevation of activation- and

3 cytotoxicity-associated genes. (A) Schematic diagram of isolating CD11a $\mathrm{a}^{\text {high }} \mathrm{CD} 4^{+}$

4 and CD11a $\mathrm{a}^{\text {low }} \mathrm{CD}_{4} 9 \mathrm{~d}^{-} \mathrm{CD}^{+} \mathrm{T}$ cell subsets in saline or P-KFD1 intranasally

$5 \quad$ immunized mice on 4 dpi. (B) Overview of sc-RNA seq of pulmonary CD4 ${ }^{+} \mathrm{T}$ cells.

$6 \quad$ FACS sorted CD11a ${ }^{\text {low }} \mathrm{CD} 49 \mathrm{~d}^{-} \mathrm{CD} 4^{+} \mathrm{T}$ cells were labeled by hashtag antibody and

7 mixed with CD11 $\mathrm{a}^{\text {high }} \mathrm{CD} 4^{+} \mathrm{T}$ cells at a ratio of approximately 3:5 before sc-RNA seq

8 of mRNA and TCR. (C) Clustering results and hashtag analysis of sc-RNA seq. Each

9 point represents one single barcode labeled cell and each cluster was displayed in the

10 t-SNE plots established by total mRNA. Pie charts exhibited percentages of detected

11 barcodes in each cluster. (D) Heatmap of clustering identification associated signature

12 differential expression genes (DEGs) in each cluster. Each vertical line represents a

13 single cell. (E) Volcano plot of DEGs in cells exclusion of clusters 1, 3 and 7 between

14 P-KFD1 group versus saline group. (F) Enriched KEGG pathways and GO terms for

15 DEGs in non-naive cells excluded clusters 1, 3 and 7 between P-KFD1 group versus

16 saline group. (G) T-SNE plots for gene expression of DEGs Il17a, Rorc, Lta and Il2ra.

17 See also Figure S5. 
2 Figure 6. Clonal expansion of Th17 cells and P-specific $\mathrm{IL}_{-17 \mathrm{~A}^{+}} \mathrm{T}$ cell response

3 in P-KFD1 intranasally immunized mice on 4 dpi. (A-D) TCR sequencing analysis.

4 (A) T-SNE plots for TCR sequencing detected barcodes (upper panel) and repeatedly

5 used TCRs barcodes (lower panel). (B) The association between the number of CD4 ${ }^{+}$

6 T cell clonotypes and the number of cells per clonotype in saline and P-KFD1 groups.

7 (C) Volcano plot of DEGs in cells with repeatedly used TCRs between P-KFD1

8 group versus saline group. (D) Violin plots of some significant DEGs in cells with

9 repeatedly used TCRs. (E) ELISpot assay of P-specific IL-17A ${ }^{+} \mathrm{T}$ cell response of

10 pulmonary immunocytes on 4 dpi. $n=6$ mice per group. Data are represented as mean

$11 \pm$ SEM of at least two independent experiments for Figure $6 \mathbf{E}$, and groups were

12 compared using regular two-way ANOVA. *** $\mathrm{p}<0.001$. See also Figure S6. 
2 Figure 7. P-specific Th1 and Th17 immune responses induced by P-KFD1 i.n.

3 immunization contribute to protection. (A to E) Adoptive transfer experiment. (A)

4 Flow diagram of adoptive transfer experiment. (B) Representative plots of

5 immunocytes in lungs and spleens of recipient mice with or without CFSE-labeled

6 cells. (C) Percentages of proliferated $\mathrm{CD}^{+}, \mathrm{CD}^{+} \mathrm{T}$ cells and B cells from immunized

7 donors in lungs and spleens of recipients were evaluated at 4 dpi, $n=5$ mice per

8 group. (D and E) With PMA and ionomycin stimulation, percentages of IFN- $\gamma^{+}$,

$9 \mathrm{IL}_{-17 \mathrm{~A}^{+}}$or $\mathrm{IL}-4^{+}$cells in $\mathrm{CFSE}^{-} \mathrm{CD}^{+}$or $\mathrm{CFSE}^{+} \mathrm{CD}^{+} \mathrm{T}$ cells in lungs (D) and

10 spleens (E) of recipients were assessed at 4 dpi, $n=4 \sim 5$ mice per group. (F) Saline or P-KFD1 intranasally immunized mice were treated with antibodies to block IFN- $\gamma$, IL-17A or both IFN- $\gamma$ and IL-17A during RSV infection, respectively, viral loads were assessed on 4 dpi, $n=4 \sim 5$ mice per group. Data are represented as mean \pm SEM of at least two independent experiments. In Figures $\mathbf{7 C}$ and $\mathbf{7 F}$, groups were compared using regular two-way ANOVA. In Figures 7D and 7E, groups were compared using one-way ANOVA. $* \mathrm{p}<0.05, * * \mathrm{p}<0.01, * * * \mathrm{p}<0.001$, ns means non-significant. See also Figure S7.

STAR Methods

\section{Lead contact}


1 Further information and requests for resources and reagents should be directed to and

2 will be fulfilled by the Lead Contact, Huimin Yan (yanhuimin@shphc.org.cn)

3 Materials Availability

4 This study did not generate new unique reagents.

5 Data and Code Availability

6 EXPERIMENTAL MODEL AND SUBJECT DETAILS

7 Mice

8 Female 6-8-week-old BALB/c mice were purchased from Beijing Vital River

9 Laboratory Animal Technology Co. Ltd, Beijing, China. $\mathrm{pIgR}^{-/-}$mice on a BALB/c background were obtained from the Mutant Mouse Resource and Research Centers

11 (MMRRCs), bred and housed at the Animal Center of Wuhan Institute of Virology

12 (WIV), Chinese Academy of Science (CAS). Mice were randomly assigned to groups.

All mice were raised in individually ventilated cages (IVCs) under specific pathogen-free (SPF) conditions. The infection experiments were performed in the Animal Biosafety Level 2 (ABSL-2) Laboratory at WIV, CAS. Animal studies were approved by the Animal Welfare and Ethical Review Committee of WIV, and conducted according to Regulations for the Administration of Affairs Concerning

Experimental Animals in China (study numbers WIVA09201505 and WIVA09201901).

\section{Cell lines}

HEp-2 cells were obtained from the China Center for Type Culture Collection

(CCTCC), Vero C1008 cells (CRL-1587) and Caco-2 cells (HTB-37) were obtained 
1 from the American type culture collection (ATCC). All three cell lines were grown in

2 Dulbecco's modified Eagle's (DMEM) medium, supplemented with 10\% (v/v) FBS

3 and $1 \%$ (v/v) Penicillin/Streptomycin at $37^{\circ} \mathrm{C}$ in $5 \% \mathrm{CO}_{2}$.

$4 \quad$ Virus

5 Human respiratory syncytial virus (hRSV) strain A2 provided by Professor Pan

6 (Wuhan University) was propagated in HEp-2 or Vero cells.

\section{Vaccination}

Mice were intranasally (i.n.) immunized three times with P-KFD1 or P+CTB at four-week intervals after anesthesia with pentobarbital sodium $(50 \mathrm{mg} / \mathrm{kg})$, and were challenged with 2 × $10^{6}$ PFU of RSV A2 on 28 days post last immunization.

Mice were intramuscularly (i.m.) immunized with FI-RSV in the lower hind limb twice at a two-week interval and were challenged with RSV A2 14 days post boost immunization.

\section{CFSE labeling and adoptive transfer model}

Donor mice were immunized with saline (i.n. or i.m.), KFD1 (i.n.), P-KFD1 (i.n.), P+CTB (i.n.) or FI-RSV (i.m.) as described above. Splenocytes were separated from donor mice at 7 days post second boost immunization and were labeled with $10 \mu \mathrm{M}$ of CFSE for 10 minutes at room temperature. After washing, CFSE-labeled splenocytes were resuspended in PBS and intravenously injected into naïve mice. Twelve hours post transfer, recipient mice were infected with RSV A2 and sacrificed at 4 days post infection (dpi). Pulmonary and splenic lymphocytes of recipient mice were harvested on 4 dpi for proliferation and Th-bias assay. 


\section{METHOD DETAILS}

\section{Vaccine preparation}

3 RSV $P$ gene was connected to the 5' flanking region of the $D 0-D 1$ genes of flagellin

$4 \mathrm{KF}$ (E.coli K12 strain MG1655) to construct the P-KFD1 gene, which was then

5 cloned into pET-30a plasmid vector (Invitrogen). The recombinant RSV P protein,

6 RSV N protein, HIV-1 p24 protein and P-KFD1 protein were induced, expressed in

7 E.coli BL21 DE3, purified by affinity chromatography on a Ni-NTA column (Qiagen),

8 and removed contaminating lipopolysaccharide (LPS), respectively, as previously

9 described (Yang et al., 2013). The residual LPS content was determined using the Limulus assay (Associates of Cape Cod) to be less than $0.01 \mathrm{EU} / \mu \mathrm{g}$ protein.

FI-RSV vaccine was prepared as described elsewhere (Kim et al., 1969; Waris et al., 1996). Briefly, clarified RSV-infected HEp-2 cell culture supernatant was incubated with neutral formalin $(1: 4000)$ for 72 hours at $37^{\circ} \mathrm{C}$, and the resulting pellet was resuspended and precipitated with Imject Alum adjuvant (Thermo Fisher Scientific) before use.

\section{RSV preparation and inoculation}

RSV-infected HEp-2 cells were sonicated and concentrated by ultracentrifugation (BECKMAN, Optima XPN) at 70,000 $\mathrm{x} g$ for 2 hours at $4^{\circ} \mathrm{C}$. The resultant precipitate was resuspended with DMEM. After centrifugation at $10,000 \times g$ for 10 minutes at $4^{\circ} \mathrm{C}$, the obtained supernatant was stored at $-80^{\circ} \mathrm{C}$ as $\mathrm{RSV}$ stock. Mice were intranasally inoculated with $2 \times 10^{6} \mathrm{PFU}$ of RSV A2 in $100 \mu \mathrm{L}$ under avertin (250 $\mathrm{mg} / \mathrm{kg}$ ) anesthesia. 


\section{Tissue collection and virus titration}

2 RSV-infected mice were sacrificed, noses and the left lungs were removed and placed

3 in a 2-mL screw cap tube containing sterile $1-\mathrm{mm}$ diameter ceramic beads and $1 \mathrm{~mL}$

4 Hanks balanced salt solution (HBSS) containing $25 \quad \mathrm{mM}$

5 N-2-hydroxyethylpiperazine-N'-2-ethanesulfonic acid ( $\mathrm{pH} 7.8), 200 \mathrm{U}$ of penicillin

6 and streptomycin, $0.218 \mathrm{M}$ sucrose, $4.8 \mathrm{mM}$ glutamate, and $30 \mathrm{mM}$ magnesium

7 chloride (Taylor et al., 1984; Waris et al., 1996). The tubes were quick-frozen in

8 liquid nitrogen. Then the tissue homogenates were prepared using a BeadBeater

9 homogenizer (Biospec Products) for 4 minutes with intermittent cooling in ice bath

10 (Waris et al., 1996). Virus stocks or tissue homogenates from infected mice were

11 titrated by immuno-plaque assay as described elsewhere (Quan et al., 2011). Titers

12 were recorded as PFU/nose or PFU/g lung.

\section{Enzyme-Linked Immunosorbent Assay (ELISA)}

Antibody responses were assessed by enzyme-linked immunosorbent assay (ELISA). In brief, a 96-well plate was coated with target protein $(3 \mu \mathrm{g} / \mathrm{mL})$ in carbonate-bicarbonate buffer at $4^{\circ} \mathrm{C}$ overnight and then blocked with $1 \%$ BSA at $37^{\circ} \mathrm{C}$ for 2 hours. Then serial four-fold diluted samples were added to the plates for 2 hours at $37^{\circ} \mathrm{C}$. After washing, secondary alkaline phosphatase-labeled antibodies (SouthernBiotech) were applied to the plates followed by substrate (p-nitrophenyl phosphate, Sigma) coloring. ODs were read at $405 \mathrm{~nm}$ by an ELISA plate reader (Thermo Labsystems). 

detected by ELISA kits (eBioscience) under the manufacturer's instructions.

\section{Airway responses to methacholine challenge}

Airway responsiveness was assessed in mice using an AniRes2005 lung function system (Bestlab, version 2.0, China) according to the manufacturer's instructions, as described previously (Drazen et al., 1999; Guo et al., 2012). Briefly, anesthetized mice were ventilated via a tracheal cannula which was connected to an animal ventilator, then methacholine was administered through a catheter into the jugular vein with increasing concentrations $(0.025,0.05,0.1$ and $0.2 \mathrm{mg} / \mathrm{kg})$ at 5 -minute intervals. The relative area ( $\mathrm{R}$-area) was defined as the area between the peak value and baseline of $\mathrm{Ri}$ or Re during a 250 -second period, and the valley value of Cdyn was used to describe lung compliance.

\section{Histology}

Lungs of mice were excised and fixed in $10 \%$ neutral buffered formalin for 24 hours at room temperature, followed by embedding in paraffin. After cutting into slices, tissues were stained with hematoxylin \& eosin (H\&E) or periodic acid-Schiff (PAS). Whole slide imaging was observed using the slide scanner Pannoramic MIDI (3DHISTECH). Pathological changes were evaluated as described elsewhere and scored on a 1-4 severity scale (Knudson et al., 2015). Scores of inflammatory cell aggregation and interstitial pneumonia scale: 1-normal naïve parameters, 2-slight and occasional cell aggregation, 3-moderate cell infiltration, 4-moderate to severe and multifocal cell aggregation around bronchioles or pulmonary vessels or air space of 
1 lung sections. Scores of mucus production scale: 1-no mucus detectable, 2-rare mucus,

2 3-moderate mucus accumulation, 4-severe mucus production in airways.

\section{Isolation of immunocytes from tissues}

4 For isolation of pulmonary immunocytes in mice, lungs were removed and cut into

5 pieces and digested in $2 \mathrm{~mL}$ of HBSS buffer (HyClone) containing $0.5 \mathrm{mg} / \mathrm{mL}$

6 collagenase 1 (Gibco) and $0.2 \mathrm{mg} / \mathrm{mL}$ Dnase 1 (Sigma) for 45 minutes at $37^{\circ} \mathrm{C}$. After

7 digestion, lung pieces were pressed through a 70- $\mu$ m nylon mesh screen, and the

8 resulting single-cell suspensions were collected and washed with cold phosphate

9 buffer saline (PBS). Then the cell pellets were resuspended in $40 \%$ Percoll (GE Healthcare) and layered carefully onto $70 \%$ Percoll to generate discontinuous Percoll 11 gradients and centrifuged at $2000 \mathrm{rpm}$ for 25 minutes at $22^{\circ} \mathrm{C}$. Cells were aspirated in the interface between $40 \%$ and $70 \%$ Percoll gradients.

For isolation of splenic lymphocytes in mice, spleens were minced and pressed through the $70-\mu \mathrm{m}$ nylon mesh screen. Lymphocytes were obtained by density centrifugation described above using Mouse Lymphocytes Separation Medium

16 (Dakewe).

\section{Flow cytometry}

To detect the number of eosinophils and $\mathrm{T}$ cells in lung, single-cell suspensions from lungs were incubated with anti-CD16/CD32 (93) to block nonspecific Fc receptor binding. Then cells were surface-stained with monoclonal antibodies specific to CD45

CD8 (53-6.7) and fixable viability dye (eBioscience) or 7-AAD viability staining 
1 solution (BioLegend) at $4^{\circ} \mathrm{C}$ for 30 minutes. For Th bias assay, separated cells were

2 stimulated for 5 hours at $37^{\circ} \mathrm{C}$ with $200 \mathrm{ng} / \mathrm{mL}$ PMA (Beyotime) and $2000 \mathrm{ng} / \mathrm{mL}$

3 ionomycin (Beyotime) in the presence of brefeldin A (BioLegend) and monensin

4 (BioLegend). Then cells were labeled with fixable viability dye and mAbs specific to

5 CD4 or CD8. After washing, cells were fixed and permeabilized, using the fixation

6 buffer and Intracellular Staining Permeabilization Wash Buffer (BioLegend), and

7 stained intracellularly with mAbs specific to IFN- $\gamma$ (XMG1.2), IL-4 (11B11) and

$8 \quad$ IL-17A (eBio17B7). For detection of Treg, cells were labeled with 7-AAD viability

9 staining solution and surfaced-stained with mAbs specific to CD4 and CD25 (PC61)

10 and then fixed and permeabilized with Foxp3/Transcription Factor Staining Buffer Set

11 (eBioscience) prior to incubation with mAb specific to Foxp3 (FJK-16s). For

12 detection of cell proliferation, pulmonary and splenic lymphocytes of recipient mice

13 were separated and stained with fixable viability dye and mAbs specific to CD4, CD8, 14 and B220 (RA3-6B2) to analyze the expanded CFSE-labeled $\mathrm{CD}^{+}{ }^{+} \mathrm{T}$ cells, $\mathrm{CD}^{+} \mathrm{T}$ 15 cells and B cells by flow cytometry. All antibodies were bought from BD Bioscience, eBioscience or BioLegend. Stained cells were run on an LSRFortessa (BD, Heidelberg, Germany) and analyzed with FlowJo software (Tree Star, Ashland, OR).

\section{Enzyme-Linked Immunospot (ELISpot) Assay}

Mouse IFN- $\gamma$ (Dakewe), mouse IL-17A (Mabtech) and mouse IL-4 (Dakewe) secreting cells were detected by ELISpot following the manufacturer's instructions. 
$15 \% \mathrm{CO}_{2}$, respectively. After cell lysis, biotin-conjugated mAbs were applied prior to

2 adding streptavidin-HRP, and then spots were developed with an AEC coloring

3 system. The number of spots was counted by an automatic ELISpot reader (AID,

4 Germany).

5 Serum transfer

6 Serum from saline, FI-RSV (i.m.) or P-KFD1 (i.n.) immunized mice were collected at

$7 \quad 14$ days post last immunization and inactivated at $56^{\circ} \mathrm{C}$ for 30 minutes. Then, $250 \mu \mathrm{L}$

8 of filtered serum were injected into naïve recipient (per mouse), respectively,

9 followed by RSV infection.

In vivo antibody treatment

11 For depletion of $\mathrm{CD}^{+}, \mathrm{CD}^{+}$, or both $\mathrm{CD}^{+}$and $\mathrm{CD}^{+} \mathrm{T}$ cells, mice were 12 intraperitoneally injected with $250 \mu \mathrm{g}$ of $\alpha$-CD4 antibody (GK1.5), $250 \mu \mathrm{g}$ of $\alpha$-CD8 antibody (2.43) or $250 \mu \mathrm{g}$ of $\alpha$-CD4 antibody plus $250 \mu \mathrm{g}$ of $\alpha$-CD8 antibody two days before RSV infection, respectively. Depletion antibodies were injected twice at a four-day interval (Knudson et al., 2015). Mice treated with the same doses of isotype-matched rat IgG2b (LTF-2) antibody were designed as controls. intraperitoneally injected with $250 \mu \mathrm{g}$ of $\alpha$ - IFN- $\gamma$ antibody (XMG1.2), $250 \mu \mathrm{g}$ of $\alpha$-IL-17A antibody (17F3), or $250 \mu \mathrm{g}$ of $\alpha$-IFN- $\gamma$ antibody, together with $250 \mu \mathrm{g}$ of $\alpha$-IL-17A antibody, respectively. Blocking antibodies were injected every other day 
1 (HRPN), mouse IgG 1 (MOPC-21), or both rat IgG 1 and mouse IgG 1 were assigned

2 as isotype control groups, respectively.

All antibodies used above were purchased from Bio X Cell.

\section{FTY720 treatment}

Mice were intraperitoneally injected with $250 \mu \mathrm{L}$ of FTY720 (Sigma) at a dose of 1 $\mathrm{mg} / \mathrm{kg}$ daily beginning 3 days before RSV challenge, until they were sacrificed.

\section{Purification of splenic $\mathrm{CD4}^{+} \mathrm{T}$ cells and adoptive transfer}

Splenocytes were separated from saline or P-KFD1 immunized mice at 7 days post last immunization. Then $\mathrm{CD}^{+} \mathrm{T}$ cells were positively selected using anti-CD4 (L3T4) microbeads following the manufacturer's instructions (Miltenyi Biotec, Germany). The purity of sorted $\mathrm{CD}^{+} \mathrm{T}$ cells was at least 95\%. Naïve recipient mice were intravenously injected with $3 \times 10^{6}$ purified $\mathrm{CD}^{+} \mathrm{T}$ cells 12 hours prior to RSV challenge and sacrificed at 4 days post infection.

\section{FACS sorting, co-culture and sc-RNA seq}

Firstly, $\mathrm{CD}^{+} \mathrm{T}$ cells were positively isolated by magnetic sorting (Miltenyi Biotec, Germany) from pulmonary immunocytes of saline or P-KFD1 intranasally immunized mice on 4 dpi. Then the purified $\mathrm{CD}^{+} \mathrm{T}$ cells were stained with monoclonal antibodies specific to CD3 (clone 145-2C11), CD4 (clone RM4-5), CD11a (clone M17/4), CD49d (clone 9C10) and 7-AAD viability staining solution (BioLegend) for FACS sorting on a FACSAriaIII (BD, Heidelberg, Germany).

For detection of P-specific immune responses, the FACS sorted CD11a ${ }^{\text {high }}$ CD4 ${ }^{+}$ T cells and CD11a ${ }^{\text {low }} \mathrm{CD} 49 \mathrm{~d}^{-} \mathrm{CD} 4^{+} \mathrm{T}$ cells were stimulated with RSV P protein or 
1 irrelevant protein or medium alone in 96-well plates for 48 hours, respectively. In

2 detail, $3 \times 10^{4}$ sorted cells were co-cultured with $1 \times 10^{4}$ naïve mice derived splenocytes

3 in a well. And the collected cell supernatants were used to detect the amount of IFN- $\gamma$,

$4 \quad$ IL-4 and IL-17A by ELISA.

For sc-RNA seq, FACS sorted CD11a ${ }^{\text {low }} \mathrm{CD} 49 \mathrm{~d}^{-} \mathrm{CD} 4^{+} \mathrm{T}$ cells were labelled by

6 TotalSeq $^{\mathrm{TM}}$ anti-mouse Hashtag antibody (BioLegend) and then mixed with the

7 corresponding $\mathrm{CD} 11 \mathrm{a}^{\text {high }} \mathrm{CD} 4^{+} \mathrm{T}$ cells at a ratio approximately 3:5. Sc-RNA seq

8 library preparation was conducted under the manufacturer's instructions for the $10 \mathrm{x}$

9 Genomics 5' v1.0 chemistry with immune profiling and feature barcoding technology

10 for cell surface protein. Briefly, 14000 cells were loaded on the chip which targeted

118000 cells corresponding to the manufacturer's guidance. A single cell, a barcoded gel

12 bead, and reverse transcriptase reagent were encapsulated into a

Gel-Bead-In-EMulsion (GEM). GEMs were transferred to the 8-tube strip and incubated at $53^{\circ} \mathrm{C}, 45 \mathrm{~min}$ followed by $85^{\circ} \mathrm{C}, 5 \mathrm{~min}$ for reverse transcription and enzyme inactivation respectively. Initial amplification of cDNA and library preparation were carried out with 13 and 14 cycles of amplification, respectively; $\mathrm{V}(\mathrm{D}) \mathrm{J}$ libraries were generated corresponding to each 5' gene expression library using both 10 cycles for the two enrichment PCRs and 10 cycles for the library amplification, respectively (Ni et al., 2020). TotalSeq ${ }^{\mathrm{TM}}$-A Hashtag antibodies which were not compatible with the standard cell surface protein library procedure were used in this study. Therefore, the Hashtag cell surface libraries were constructed as 
1 adaptor, then with the indexing PCR to get the Hashtag libraries. Libraries were

2 sequenced on Illumina NovaSeq6000 sequencing platform with the following read

3 lengths: read 1-150 cycles; read 2-150 cycles; and i7 index-8 cycles.

$4 \quad$ Single cell transcriptome analysis

5 The Cell Ranger Single-Cell Software Suite (versions 3.0.2) were used to perform

6 barcode processing and single-cell gene counting (Paulson et al., 2018)

7 (http://10xgenomics.com/). First, "cellranger mkfastq" was carried to generated fastq

8 files. Second, feature-barcode matrices were generated by "cellranger count" function

9 using GRCm38 mouse as reference genome (Ensembl). Then the cell ranger aggregation function (aggr) was used to combine the two libraries. A correction for sequencing depth was also performed during the aggregation. IntegrateData function in $\mathrm{R}$ package Seurat V3.6.3 was used to merge Saline and P-KFD1 fastq data. Low-quality genes and cells were filtered by removing cells with 1) expressed genes fewer than 200,2) expressed genes more than 5,000,3) percentages of mitochondrial genes $>20 \%$ and 4) genes expressed in less than 3 cells. The filtered gene-barcode matrix was first normalized using "LogNormalize" method. The top 2,000 variable genes were then identified using the "vst" method in Seurat FindVariableFeatures function. Principal component analysis (PCA) was performed using variable genes, and the top 20 principal components (PCs) were used to perform t-distributed Stochastic Neighbor Embedding (t-SNE) to visualize the cells. The resolution was set to 0.5 for clustering. T-SNE coordinate points and cell clusters were exported into 
1 analyze data. For the TCR data, the Cell Ranger Single-Cell Software Suite (versions

2 3.0.2) were used to perform barcode processing, assembly contig, cell calling,

3 annotation the contigs and CDR3 region for each clonotype. KEGG (Kyoto

4 Encyclopedia of Genes and Genomes) pathways and GO (Gene ontology) terms

5 analysis were performed as follows: genes with Benjamini-Hochberg-adjusted P value

$6<0.05$ and $\log _{2}|\mathrm{FC}|$ between two groups larger than 1 were used for DAVID analysis

7 (Guo et al., 2018) (https://david-d.ncifcrf.gov/).

\section{QUANTIFICATION AND STATISTICAL ANALYSIS}

9 Statistical parameters including the exact value of $n$, the definition of center, dispersion, and precision measures (geometric mean \pm SEM) and statistical significance are displayed in Figures and Figure Legends. Data were considered to be statistically significant if $\mathrm{p}<0.05$. All statistical analyses were performed using GraphPad Prism version 5.0 (GraphPad Software, San Diego, CA). Data were compared using unpaired, two-tailed $t$ test between two groups or one-way ANOVA with Tukey's multiple comparison for more than two groups. Data were also analyzed by regular two-way ANOVA if two independent variables existed in one experiment.

\section{REFERENCES}

Asahi, Y., Yoshikawa, T., Watanabe, I., Iwasaki, T., Hasegawa, H., Sato, Y., Shimada, S., Nanno, M., Matsuoka, Y., Ohwaki, M., et al. (2002). Protection against influenza virus infection in polymeric Ig receptor knockout mice immunized intranasally with adjuvant-combined vaccines. J Immunol 168 , 2930-2938. Bacher, P., Hohnstein, T., Beerbaum, E., Rocker, M., Blango, M.G., Kaufmann, S., Rohmel, J., Eschenhagen, P., Grehn, C., Seidel, K., et al. (2019). Human Anti-fungal Th17 Immunity and 
Bao, R., Yang, J.Y., Sun, Y., Zhou, D.H., Yang, Y., Li, Y.M., Cao, Y., Xiao, Y., Li, W., Yu, J., et al. (2015). Flagellin-PAc Fusion Protein Inhibits Progression of Established Caries. J Dent Res 94, 955-960.

Blount, R.E., Jr., Morris, J.A., and Savage, R.E. (1956). Recovery of cytopathogenic agent from chimpanzees with coryza. Proc Soc Exp Biol Med 92, 544-549.

Brinkmann, V., Davis, M.D., Heise, C.E., Albert, R., Cottens, S., Hof, R., Bruns, C., Prieschl, E., Baumruker, T., Hiestand, P., et al. (2002). The immune modulator FTY720 targets sphingosine 1-phosphate receptors. J Biol Chem 277, 21453-21457.

Bueno, S.M., Gonzalez, P.A., Cautivo, K.M., Mora, J.E., Leiva, E.D., Tobar, H.E., Fennelly, G.J., Eugenin, E.A., Jacobs, W.R., Jr., Riedel, C.A., et al. (2008). Protective T cell immunity against respiratory syncytial virus is efficiently induced by recombinant BCG. Proc Natl Acad Sci U S A 105, 20822-20827.

Burns, J.W., Siadat-Pajouh, M., Krishnaney, A.A., and Greenberg, H.B. (1996). Protective effect of rotavirus VP6-specific IgA monoclonal antibodies that lack neutralizing activity. Science 272 , 104-107.

Cautivo, K.M., Bueno, S.M., Cortes, C.M., Wozniak, A., Riedel, C.A., and Kalergis, A.M. (2010). Efficient lung recruitment of respiratory syncytial virus-specific Th1 cells induced by recombinant bacillus Calmette-Guerin promotes virus clearance and protects from infection. J Immunol 185, 7633-7645.

Chanock, R., and Finberg, L. (1957). Recovery from infants with respiratory illness of a virus related to chimpanzee coryza agent (CCA). II. Epidemiologic aspects of infection in infants and young children. Am J Hyg 66, 291-300.

Chemaly, R.F., Shah, D.P., and Boeckh, M.J. (2014). Management of respiratory viral infections in hematopoietic cell transplant recipients and patients with hematologic malignancies. Clin Infect Dis 59 Suppl 5, S344-351.

Chin, J., Magoffin, R.L., Shearer, L.A., Schieble, J.H., and Lennette, E.H. (1969). Field evaluation of a respiratory syncytial virus vaccine and a trivalent parainfluenza virus vaccine in a pediatric population. Am J Epidemiol 89, 449-463.

Crank, M.C., Ruckwardt, T.J., Chen, M., Morabito, K.M., Phung, E., Costner, P.J., Holman, L.A., Hickman, S.P., Berkowitz, N.M., Gordon, I.J., et al. (2019). A proof of concept for structure-based vaccine design targeting RSV in humans. Science 365, 505-509.

Donnelly, M.A., and Steiner, T.S. (2002). Two nonadjacent regions in enteroaggregative Escherichia coli flagellin are required for activation of toll-like receptor 5. J Biol Chem 277, 40456-40461.

Drazen, J.M., Finn, P.W., and De Sanctis, G.T. (1999). Mouse models of airway responsiveness: physiological basis of observed outcomes and analysis of selected examples using these outcome indicators. Annu Rev Physiol 61, 593-625.

Eliasson, D.G., Omokanye, A., Schon, K., Wenzel, U.A., Bernasconi, V., Bemark, M., Kolpe, A., El Bakkouri, K., Ysenbaert, T., Deng, L., et al. (2018). M2e-tetramer-specific memory CD4 T cells are broadly protective against influenza infection. Mucosal Immunol 11, 273-289.

Falsey, A.R., Hennessey, P.A., Formica, M.A., Cox, C., and Walsh, E.E. (2005). Respiratory syncytial virus infection in elderly and high-risk adults. N Engl J Med 352, 1749-1759.

Fulginiti, V.A., Eller, J.J., Sieber, O.F., Joyner, J.W., Minamitani, M., and Meiklejohn, G. (1969). Respiratory virus immunization. I. A field trial of two inactivated respiratory virus vaccines; an 
aqueous trivalent parainfluenza virus vaccine and an alum-precipitated respiratory syncytial virus vaccine. Am J Epidemiol 89, 435-448.

Glezen, W.P., Taber, L.H., Frank, A.L., and Kasel, J.A. (1986). Risk of primary infection and reinfection with respiratory syncytial virus. Am J Dis Child 140, 543-546.

Graham, B.S., Modjarrad, K., and McLellan, J.S. (2015). Novel antigens for RSV vaccines. Curr Opin Immunol 35, 30-38.

Group, P.E.R.f.C.H.S. (2019). Causes of severe pneumonia requiring hospital admission in children without HIV infection from Africa and Asia: the PERCH multi-country case-control study. Lancet 394, 757-779.

Group, T.I.-R.S. (1998). Palivizumab, a Humanized Respiratory Syncytial Virus Monoclonal Antibody, Reduces Hospitalization From Respiratory Syncytial Virus Infection in High-risk Infants. Pediatrics 102, 531-537.

Guo, J., Han, B., Qin, L., Li, B., You, H., Yang, J., Liu, D., Wei, C., Nanberg, E., Bornehag, C.G., et al. (2012). Pulmonary toxicity and adjuvant effect of di-(2-exylhexyl) phthalate in ovalbumin-immunized BALB/c mice. PLoS One 7, e39008.

Guo, X., Zhang, Y., Zheng, L., Zheng, C., Song, J., Zhang, Q., Kang, B., Liu, Z., Jin, L., Xing, R., et al. (2018). Global characterization of T cells in non-small-cell lung cancer by single-cell sequencing. Nat Med 24, 978-985.

Guvenel, A., Jozwik, A., Ascough, S., Ung, S.K., Paterson, S., Kalyan, M., Gardener, Z., Bergstrom, E., Kar, S., Habibi, M.S., et al. (2020). Epitope-specific airway-resident CD4+ T cell dynamics during experimental human RSV infection. J Clin Invest 130, 523-538.

Henderson, F.W., Collier, A.M., Clyde, W.A., Jr., and Denny, F.W. (1979). Respiratory-syncytial-virus infections, reinfections and immunity. A prospective, longitudinal study in young children. N Engl J Med 300, 530-534.

Iwanaga, N., and Kolls, J.K. (2019). Updates on T helper type 17 immunity in respiratory disease. Immunology 156, 3-8.

Johnson, T.R., Johnson, J.E., Roberts, S.R., Wertz, G.W., Parker, R.A., and Graham, B.S. (1998). Priming with secreted glycoprotein G of respiratory syncytial virus (RSV) augments interleukin-5 production and tissue eosinophilia after RSV challenge. J Virol 72, 2871-2880.

Kapikian, A.Z., Mitchell, R.H., Chanock, R.M., Shvedoff, R.A., and Stewart, C.E. (1969). An epidemiologic study of altered clinical reactivity to respiratory syncytial (RS) virus infection in children previously vaccinated with an inactivated RS virus vaccine. Am J Epidemiol 89, 405-421. Kim, H.W., Canchola, J.G., Brandt, C.D., Pyles, G., Chanock, R.M., Jensen, K., and Parrott, R.H. (1969). Respiratory syncytial virus disease in infants despite prior administration of antigenic inactivated vaccine. Am J Epidemiol 89, 422-434.

Knudson, C.J., Hartwig, S.M., Meyerholz, D.K., and Varga, S.M. (2015). RSV vaccine-enhanced disease is orchestrated by the combined actions of distinct CD4 T cell subsets. PLoS Pathog 11, e1004757.

Knudson, C.J., Weiss, K.A., Hartwig, S.M., and Varga, S.M. (2014). The pulmonary localization of virus-specific T lymphocytes is governed by the tissue tropism of infection. J Virol 88, 9010-9016. Li, W., Zhang, X., Yang, Y., Yin, Q., Wang, Y., Li, Y., Wang, C., Wong, S.M., Wang, Y., Goldfine, H., et al. (2018). Recognition of conserved antigens by Th17 cells provides broad protection against pulmonary Haemophilus influenzae infection. Proc Natl Acad Sci U S A 115, E7149-E7157. 
Mandala, S., Hajdu, R., Bergstrom, J., Quackenbush, E., Xie, J., Milligan, J., Thornton, R., Shei, G.J., Card, D., Keohane, C., et al. (2002). Alteration of lymphocyte trafficking by sphingosine-1-phosphate receptor agonists. Science 296, 346-349.

Marcandalli, J., Fiala, B., Ols, S., Perotti, M., de van der Schueren, W., Snijder, J., Hodge, E., Benhaim, M., Ravichandran, R., Carter, L., et al. (2019). Induction of Potent Neutralizing Antibody Responses by a Designed Protein Nanoparticle Vaccine for Respiratory Syncytial Virus. Cell 176, 1420-1431 e1417.

McDermott, D.S., and Varga, S.M. (2011). Quantifying antigen-specific CD4 T cells during a viral infection: CD4 T cell responses are larger than we think. J Immunol 187, 5568-5576.

McKinstry, K.K., Strutt, T.M., Kuang, Y., Brown, D.M., Sell, S., Dutton, R.W., and Swain, S.L. (2012). Memory CD4+ $\mathrm{T}$ cells protect against influenza through multiple synergizing mechanisms. J Clin Invest 122, 2847-2856.

McLellan, J.S., Chen, M., Joyce, M.G., Sastry, M., Stewart-Jones, G.B., Yang, Y., Zhang, B., Chen, L., Srivatsan, S., Zheng, A., et al. (2013a). Structure-based design of a fusion glycoprotein vaccine for respiratory syncytial virus. Science $342,592-598$.

McLellan, J.S., Chen, M., Leung, S., Graepel, K.W., Du, X., Yang, Y., Zhou, T., Baxa, U., Yasuda, E., Beaumont, T., et al. (2013b). Structure of RSV fusion glycoprotein trimer bound to a prefusion-specific neutralizing antibody. Science 340, 1113-1117.

Meng, J., Stobart, C.C., Hotard, A.L., and Moore, M.L. (2014). An overview of respiratory syncytial virus. PLoS Pathog 10, e1004016.

Mizel, S.B., and Bates, J.T. (2010). Flagellin as an adjuvant: cellular mechanisms and potential. J Immunol 185, 5677-5682.

Mukherjee, S., Lindell, D.M., Berlin, A.A., Morris, S.B., Shanley, T.P., Hershenson, M.B., and Lukacs, N.W. (2011). IL-17-induced pulmonary pathogenesis during respiratory viral infection and exacerbation of allergic disease. Am J Pathol 179, 248-258.

Nair, H., Nokes, D.J., Gessner, B.D., Dherani, M., Madhi, S.A., Singleton, R.J., O'Brien, K.L., Roca, A., Wright, P.F., Bruce, N., et al. (2010). Global burden of acute lower respiratory infections due to respiratory syncytial virus in young children: a systematic review and meta-analysis. Lancet 375, 1545-1555.

Ni, J., Wang, X., Stojanovic, A., Zhang, Q., Wincher, M., Buhler, L., Arnold, A., Correia, M.P., Winkler, M., Koch, P.S., et al. (2020). Single-Cell RNA Sequencing of Tumor-Infiltrating NK Cells Reveals that Inhibition of Transcription Factor HIF-1alpha Unleashes NK Cell Activity. Immunity 52, 1075-1087 e1078.

Openshaw, P.J., Clarke, S.L., and Record, F.M. (1992). Pulmonary eosinophilic response to respiratory syncytial virus infection in mice sensitized to the major surface glycoprotein G. Int Immunol 4, 493-500.

Paulson, K.G., Voillet, V., McAfee, M.S., Hunter, D.S., Wagener, F.D., Perdicchio, M., Valente, W.J., Koelle, S.J., Church, C.D., Vandeven, N., et al. (2018). Acquired cancer resistance to combination immunotherapy from transcriptional loss of class I HLA. Nat Commun 9, 3868.

Quan, F.S., Kim, Y., Lee, S., Yi, H., Kang, S.M., Bozja, J., Moore, M.L., and Compans, R.W. (2011). Viruslike particle vaccine induces protection against respiratory syncytial virus infection in mice. $\mathrm{J}$ Infect Dis 204, 987-995.

Ruckwardt, T.J., Morabito, K.M., and Graham, B.S. (2019). Immunological Lessons from Respiratory Syncytial Virus Vaccine Development. Immunity 51, 429-442. 
Shao, T.Y., Ang, W.X.G., Jiang, T.T., Huang, F.S., Andersen, H., Kinder, J.M., Pham, G., Burg, A.R., Ruff, B., Gonzalez, T., et al. (2019). Commensal Candida albicans Positively Calibrates Systemic Th17 Immunological Responses. Cell Host Microbe 25, 404-417 e406.

Shi, T., McAllister, D.A., O'Brien, K.L., Simoes, E.A.F., Madhi, S.A., Gessner, B.D., Polack, F.P., Balsells, E., Acacio, S., Aguayo, C., et al. (2017). Global, regional, and national disease burden estimates of acute lower respiratory infections due to respiratory syncytial virus in young children in 2015: a systematic review and modelling study. Lancet 390, 946-958.

Shimada, S., Kawaguchi-Miyashita, M., Kushiro, A., Sato, T., Nanno, M., Sako, T., Matsuoka, Y., Sudo, K., Tagawa, Y., Iwakura, Y., et al. (1999). Generation of polymeric immunoglobulin receptor-deficient mouse with marked reduction of secretory IgA. J Immunol 163, 5367-5373.

Sun, Y., Shi, W., Yang, J.Y., Zhou, D.H., Chen, Y.Q., Zhang, Y., Yang, Y., He, B.X., Zhong, M.H., Li, Y.M., et al. (2012). Flagellin-PAc fusion protein is a high-efficacy anti-caries mucosal vaccine. J Dent Res 91, 941-947.

Taylor, G., Stott, E.J., Hughes, M., and Collins, A.P. (1984). Respiratory syncytial virus infection in mice. Infect Immun 43, 649-655.

Tebbey, P.W., Hagen, M., and Hancock, G.E. (1998). Atypical pulmonary eosinophilia is mediated by a specific amino acid sequence of the attachment $(G)$ protein of respiratory syncytial virus. J Exp Med 188, 1967-1972.

Waris, M.E., Tsou, C., Erdman, D.D., Zaki, S.R., and Anderson, L.J. (1996). Respiratory synctial virus infection in BALB/c mice previously immunized with formalin-inactivated virus induces enhanced pulmonary inflammatory response with a predominant Th2-like cytokine pattern. J Virol 70 , 2852-2860.

Wilkinson, T.M., Li, C.K., Chui, C.S., Huang, A.K., Perkins, M., Liebner, J.C., Lambkin-Williams, R., Gilbert, A., Oxford, J., Nicholas, B., et al. (2012). Preexisting influenza-specific CD4+ T cells correlate with disease protection against influenza challenge in humans. Nat Med 18, 274-280.

Wimalasundera, S.S., Katz, D.R., and Chain, B.M. (1997). Characterization of the T cell response to human rhinovirus in children: implications for understanding the immunopathology of the common cold. J Infect Dis 176, 755-759.

Yang, J., Sun, Y., Bao, R., Zhou, D., Yang, Y., Cao, Y., Yu, J., Zhao, B., Li, Y., Yan, H., et al. (2017). Second-generation Flagellin-rPAc Fusion Protein, KFD2-rPAc, Shows High Protective Efficacy against Dental Caries with Low Potential Side Effects. Sci Rep 7, 11191.

Yang, J., Zhong, M., Zhang, Y., Zhang, E., Sun, Y., Cao, Y., Li, Y., Zhou, D., He, B., Chen, Y., et al. (2013). Antigen replacement of domains D2 and D3 in flagellin promotes mucosal IgA production and attenuates flagellin-induced inflammatory response after intranasal immunization. Hum Vaccin Immunother 9, 1084-1092.

Yang, K., and Varga, S.M. (2014). Mucosal vaccines against respiratory syncytial virus. Curr Opin Virol 6, 78-84.

Yang, Y., Zhou, D., Zhao, B., Cao, Y., Yu, J., Yan, H., Zhao, W., Zhang, E., Yang, J., Zhong, M., et al. (2020). Immunoglobulin A Targeting on the N-Terminal Moiety of Viral Phosphoprotein Prevents Measles Virus from Evading Interferon-beta Signaling. ACS Infect Dis.

Zhao, J., Zhao, J., Mangalam, A.K., Channappanavar, R., Fett, C., Meyerholz, D.K., Agnihothram, S., Baric, R.S., David, C.S., and Perlman, S. (2016). Airway Memory CD4(+) T Cells Mediate Protective Immunity against Emerging Respiratory Coronaviruses. Immunity 44, 1379-1391. 
1 Zhou, D., Yang, Y., Zhao, B., Yu, J., Cao, Y., Yan, H., Zhao, W., Chen, L., Chen, F., Li, X., et al.

2 (2019). IgA targeting on the alpha-molecular recognition element (alpha-MoRE) of viral 3 phosphoprotein inhibits measles virus replication by interrupting formation and function of P-N 4 complex intracellularly. Antiviral Res 161, 144-153.

5 Zhou, D., Zhang, Y., Li, Q., Chen, Y., He, B., Yang, J., Tu, H., Lei, L., and Yan, H. (2011). Matrix

6 protein-specific IgA antibody inhibits measles virus replication by intracellular neutralization. J Virol

$7 \quad 85,11090-11097$. 


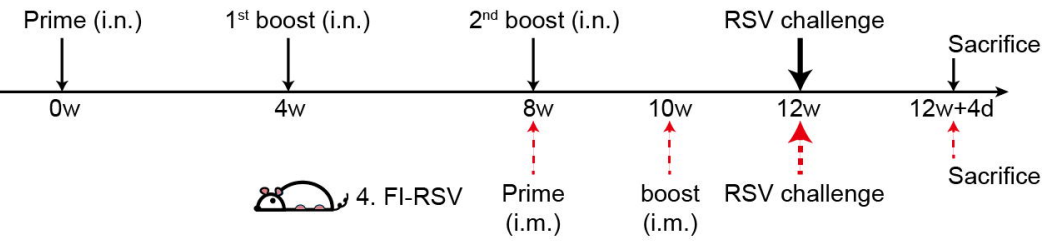

B
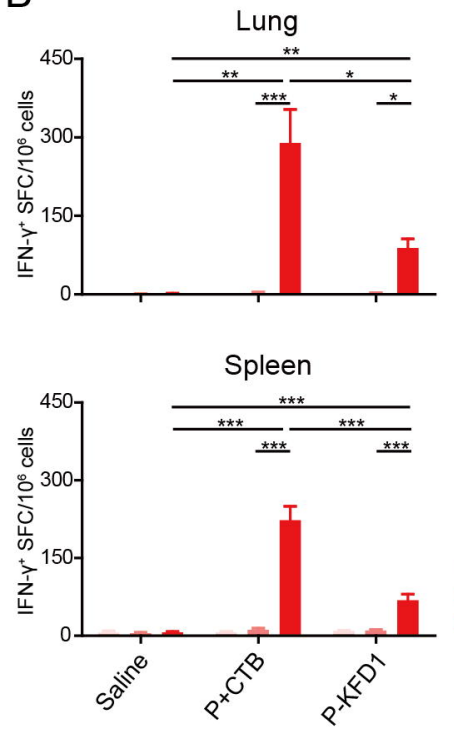

Unstimulated

Mock stimulated

RSV P stimulated
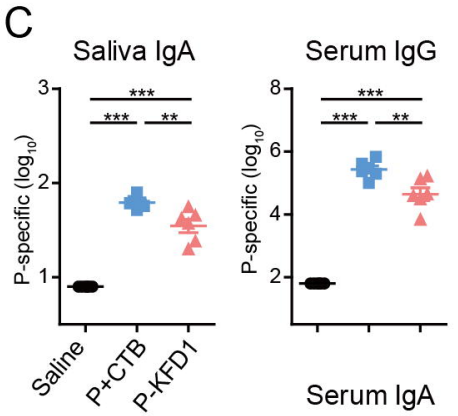

D

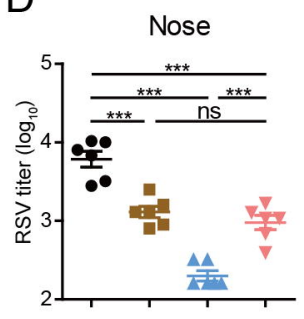

E

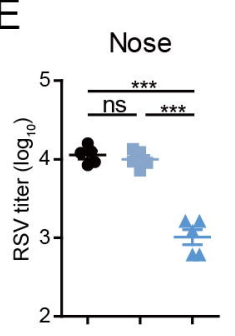

F
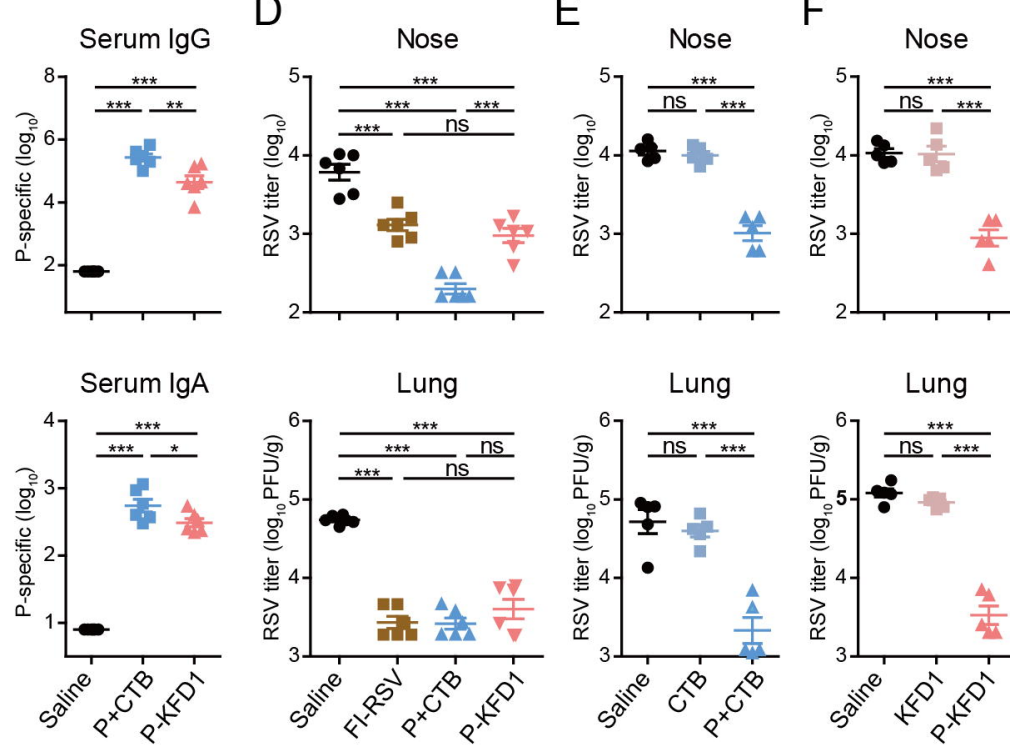
